\title{
Prognostic value and prospective molecular mechanism of miR-100-5p in hepatocellular carcinoma: A comprehensive study based on 1,258 samples
}

\author{
QING-LIN HE, SHAN-YU QIN, LIN TAO, HONG-JIAN NING and HAI-XING JIANG \\ Department of Gastroenterology, The First Affiliated Hospital of Guangxi Medical University, \\ Nanning, Guangxi Zhuang Autonomous Region 530021, P.R. China
}

Received April 12, 2019; Accepted September 6, 2019

DOI: $10.3892 / \mathrm{ol} .2019 .10962$

\begin{abstract}
The prognostic value and molecular mechanism of microRNA-100-5p (miR-100-5p) in hepatocellular carcinoma (HCC) are still unclear. To explore the prognostic value and the mechanism of miR-100-5p in HCC, the present study analyzed the results of 18 previous studies and bioinformatic datasets. The clinical significance of miR-100-5p and its targets in HCC were investigated using The Cancer Genome Atlas and the Gene Expression Omnibus, as well as relevant literature. In total, 12 online tools were used to predict the target genes of miR-100-5p. Bioinformatics analysis and Spearman correlation analysis were performed, and genomic alterations of the hub genes were evaluated. A meta-analysis with 1,258 samples revealed that miR-100-5p was significantly downregulated in HCC [standard mean difference (SMD), -0.94; 95\% confidence interval (CI), -1.14 to $\left.-0.74 ; \mathrm{I}^{2}, 35.2 \%\right]$. Lower miR-100-5p expression was associated with poorer clinical characteristics and a poorer prognosis for patients with HCC. Additionally, bioinformatics analysis revealed that the 'regulation of transcription', 'chromatin remodeling complex', 'transcription regulator activity', 'pathways in cancer' and 'heparan sulfate biosynthesis' were the most enriched terms. Furthermore, expression of histone deacetylase (HDAC)2, HDAC3, SHC-transforming protein 1 (SHC1), Ras-related protein Rac1 (RAC1) and E3 ubiquitin-protein ligase CBL (CBL) was negatively correlated with miR-100-5p
\end{abstract}

Correspondence to: Professor Hai-Xing Jiang, Department of Gastroenterology, The First Affiliated Hospital of Guangxi Medical University, 6 Shuangyong Road, Nanning, Guangxi Zhuang Autonomous Region 530021, P.R. China

E-mail: gxjianghx@163.com

Abbreviations: HCC, hepatocellular carcinoma; TCGA, The Cancer Genome Atlas; GEO, Gene Expression Omnibus; GO, Gene Ontology; KEGG, Kyoto Encyclopedia of Genes and Genomes; PPI, protein-protein interaction network; NAFLD, non-alcoholic fatty liver disease

Key words: microRNAs, miR-100-5p, hepatocellular carcinoma, target genes, prognosis, biomarkers, progression expression. Among these, upregulated HDAC2 [hazard ratio (HR), 1.910; 95\% CI, 1.309-2.787; P=0.0007], HDAC3 (HR, 1.474; 95\% CI, 1.012-2.146; P=0.0435), SHC1 (HR, 1.52; 95\% CI, 1.043-2.215; $\mathrm{P}=0.0281)$ and $\mathrm{RAC} 1(\mathrm{HR}, 1.817 ; 95 \% \mathrm{CI}$, 1.248-2.645; $\mathrm{P}=0.0022$ ) were associated with shorter survival. Alterations in HDAC2, SHC1, RAC1 and IGF1R were linked with a poorer outcome for $\mathrm{HCC}$, and alternative splicing of $\mathrm{SHC}$ and RAC1 were significantly decreased and increased in HCC, respectively. In summary, the downregulation of miR-100-5p may be involved in the progression and prognosis of HCC. The upregulation of HDAC2, HDAC3, SHC1 and RAC1 may indicate a poorer survival rate for patients with HCC. Thus, miR-100-5p and these 4 potential target genes may provide novel therapeutic targets and prognostic predictors for patients with HCC.

\section{Introduction}

In 2018, liver cancer ranked 6th in terms of incidence (841,000 new cases) and 4th in terms of overall mortality, with a mortality rate of 782,000 worldwide. Based on the histological classification of primary liver cancer, it can be divided into hepatocellular carcinoma (HCC; 75-85\%), intrahepatic cholangiocarcinoma (10-15\%), and other rare types (1). Although numerous treatment approaches are available for HCC, including liver transplantation, surgery, radiofrequency ablation, radioembolization, trans-arterial chemo-embolization and targeted therapy (2), improving the long-term survival for patients with HCC remains a challenge. Therefore, more effective molecular targets are urgently required in $\mathrm{HCC}$.

microRNAs (miRNAs/miRs) constitute a class of small noncoding RNAs, which regulate target gene expression mainly at the post-transcription level (3). Previous studies have reported that miRNAs are closely related to a number of cellular processes (CCs), including cell cycle regulation, inflammation, differentiation, migration and apoptosis, thereby performing functional roles in the occurrence and progression of various cancer types (4). A number of previous studies have shown that miRNAs can act as biomarkers and therapeutic agents to improve the diagnosis, and therapy, of cancer (5-7). Despite these previous findings, it is important to identify potential novel molecular targets. 
Recently, miR-100-5p has been identified as a biomarker in multiple types of cancer. For instance, miR-100-5p has been shown to inhibit autophagy and induce apoptosis in colorectal cancer cells by targeting autophagy protein 5 (8). Additionally, miR-100-5p enhances the chemosensitivity of breast cancer by targeting HCLS1-associated protein X-1 (9). Moreover, miR-100-5p suppresses tumor migration and invasion by targeting IGF1R in patients with nasopharyngeal carcinoma (10). miR-100-5p could also inhibit the growth and metastasis of gastric cancer by targeting zinc finger and BTB domain containing protein 7A (11). To date, few targets of miR-100-5p, such as polo like kinase 1, mammalian target of rapamycin (mTOR), Ras-related protein Rac1 (RAC1), isoprenylcystein carboxyl methyltransferase (ICMT) and insulin like growth factor 1 receptor (IGF1R), have been identified in HCC, which may be associated with tumor progression, as well as poor prognosis, due to the downregulation of miR-100-5p expression in patients with HCC (12-15). However, the previous studies were limited by small sample sizes and only several target genes of miR-100-5p have been identified in HCC. The clinical value of miR-100-5p in HCC and its molecular mechanisms are not fully understood.

In the present study, to further explore the clinical significance of miR-100-5p in HCC, the differential expression of miR-100-5p between HCC tissues and non-cancerous tissues was examined using meta-analysis based on the big data from The Cancer Genome Atlas (TCGA), The Gene Expression Omnibus (GEO) database and relevant literature (Fig. 1). The present study also attempted to reveal the clinicopathological role and prognostic value of miR-100-5p using TCGA. Bioinformatics analysis was carried out to investigate the underlying mechanism of miR-100-5p in HCC, which may provide novel therapeutic targets for HCC.

\section{Materials and methods}

Meta-analysis based on TCGA, GEO and relevant literature. Datasets about HCC were downloaded from the TCGA database (16) and were used to determine the expression level of miR-100-5p. Subsequently, the expression value of miR-100-5p was selected and converted using a $\log _{2}$ transformation. The GEO database (ncbi.nlm.nih.gov/gds/) was used to screen for HCC datasets with the keywords '(hepatocellular OR liver OR hepatoma OR hepatic) AND (carcinoma OR cancer* OR adenocarcinoma OR tumor OR malignan* OR neoplas*) AND (MicroRNA OR miRNA OR 'Micro RNA' OR mir OR 'Small Temporal RNA' OR 'non-coding RNA' OR ncRNA OR 'small RNA')' until 7th January 2019. The inclusion criteria were as follow: i) A least $3 \mathrm{HCC}$ and noncancerous tissue samples, including paracarcinoma tissue and normal liver tissue in the microarray; ii) the expression of miR-100-5p was determined and calculated; and iii) profiling obtained from Homo sapiens. miRNA-sequencing (seq) data were excluded according to the following criteria: i) The miRNA-seq did not meet the inclusion criteria; ii) the miRNA-seq did not include the expression of miR-100-5p; iii) the miRNA-seq only provided HCC tissues without noncancerous tissues; and iv) microarrays used cell line samples. For additional information about miR-100-5p in HCC, PubMed and ArrayExpress were searched until 7th January 2019 using the following search strategy: (Carcinoma OR cancer OR tumour OR tumor OR adenocarcinoma OR neoplas* OR malignan*) AND (HCC OR hepatocellular OR hepatic OR liver) AND (microRNA-100 OR miR-100 OR miRNA-100 OR miR100 OR miRNA100 OR microRNA100 OR 'miR 100' OR 'miRNA 100' OR 'microRNA 100' OR miR-100-5p OR miRNA-100-5p OR microRNA-100-5p). The inclusion criteria were as aforementioned. The number of samples, mean and standard deviation between groups were obtained for a comprehensive meta-analysis. Fixed effects, random effects models, heterogeneity and sensitivity analysis were applied in the meta-analysis using Stata SE12.0 software (Stata Corp LLC). Publication bias was determined using Egger's plot and Begg's funnel (17).

Exploring the clinical value of $m i R-100-5 p$ and its hub genes. The differential expression of miR-100-5p was computed between HCC tissues and noncancerous tissues using Student's unpaired t-test. The association between miR-100-5p levels and clinicopathological features were then evaluated based on the TCGA dataset using a Student's unpaired t-test. Patients with HCC were divided into high and low expression groups according to the median expression level. The prognostic value of miR-100-5p and its hub genes in HCC patients (survival time $>90$ days) was estimated using Kaplan-Meier analysis and log rank tests. Analysis was carried out using GraphPad Prism 7.04 (GraphPad Software, Inc.). $\mathrm{P}<0.05$ was considered to indicate a significant difference.

Predicting target genes of miR-100-5p. miRWalk 2.0 (http://zmf.umm.uni-heidelberg.de/apps/zmf/mirwalk2/) provides an intuitive interface for generating predicted and validated miRNA-binding sites for known genes in humans, mouse, rat, dog and cow (18), and was used to predict the target gees of miR-100-5p. The prospective target genes of miR-100-5p were obtained from 12 different databases (miRWalk2.0, miRanda-rel2010 (19), DIANA-microTv5.0 (20), miRNAMap2.0 (21), miRBridge4.0 (22), miRMap4.0 (23), PicTar2 (24), PITA2007 (25), miRDB4.0 (26), RNAhybrid2.1 (27), RNA22v2 (28) and TargetScan6.1 (29). The target genes of miR-100-5p that appeared in $\geq 4$ different databases were selected for further analysis.

GO and KEGG clustering analysis. DAVID 6.7 (https://david-d. ncifcrf.gov/), an online open platform that disseminates biologically abundant information across a comprehensive analysis of large gene lists, was used for clustering analysis (30). Potential target genes were searched in the annotated portal DAVID. Based on the DAVID database, enrichment annotation was performed, using GO (geneontology.org/) and KEGG (genome.jp/kegg/). Statistically significant GO and KEGG terms $(\mathrm{P}<0.05)$ were selected.

Construction of a protein-protein interaction (PPI) network. Cytoscape 3.7 (31) was used to visualize the interaction networks of hub gene products in HCC. A PPI network was constructed using the StringApp plugin, which enabled Cytoscape 3.7 to link to the STRING database (https://string-db.org/). Thereafter, the gene symbols with a degree $>7$ were selected from the PPI network, with the aim of identifying the most likely hub genes of miR-100-5p in patients with HCC. 


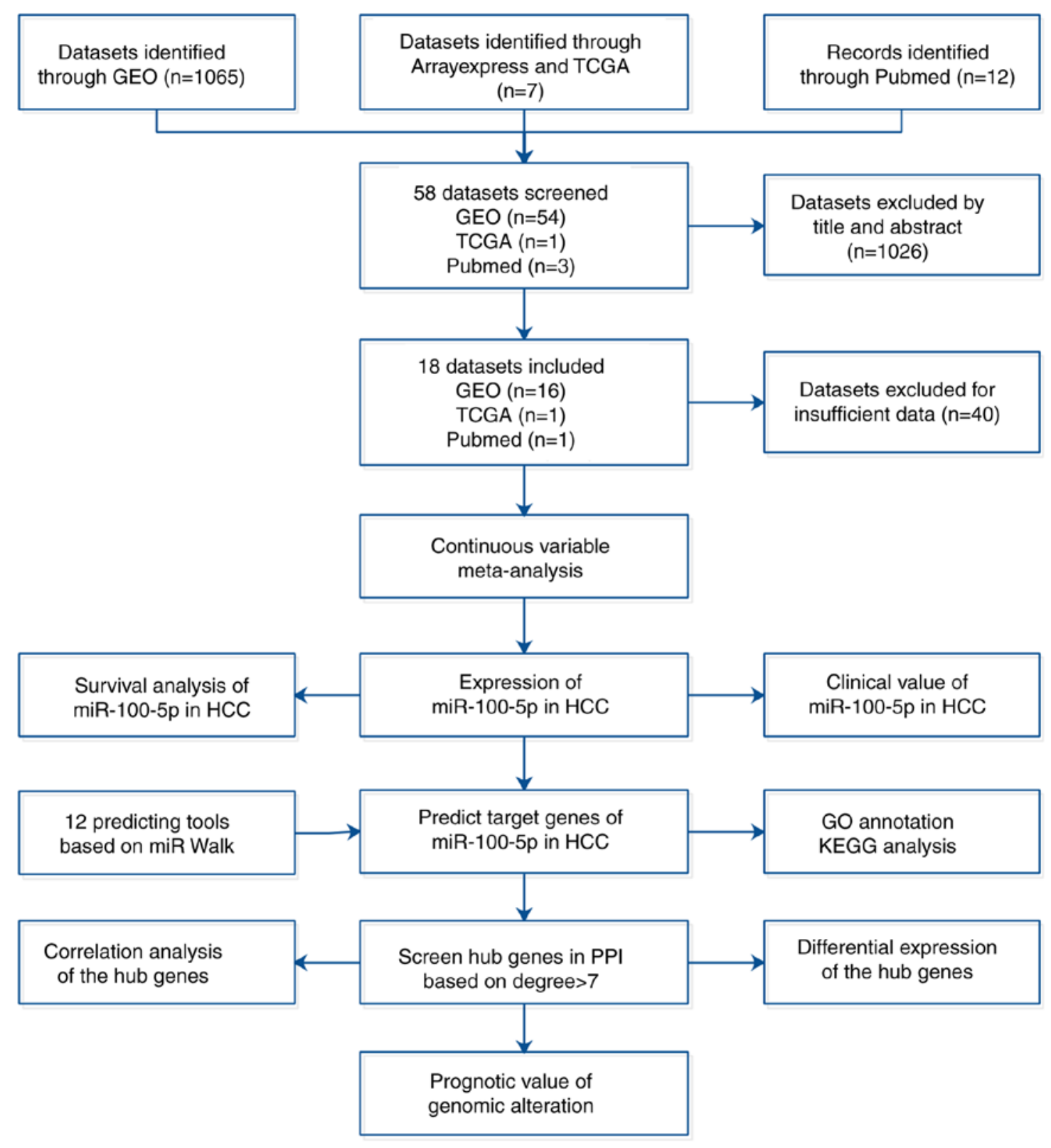

Figure 1. Flow chart of the study design.

Correlation analysis. Gene expression data ( $\log _{2}$ transformation) in HCC were downloaded from the TCGA database. In order to reveal the association between miR-100-5p and its candidate genes, Spearman's correlation analysis was performed, and linear regression plots were constructed using GraphPad Prism 7.04.

Detection of the expression of hub genes. The differential expression of the hub genes was evaluated in patients with HCC based on the Roessler's (GSE14520) (32) and Chen's dataset (GSE3500) (33) from the GEO database. Differences in the expression of the hub genes were visualized using boxplots. In addition, the protein expression of hub genes was verified using The Human Protein Atlas (proteinatlas.org), which provides a large number of antibody-based images (34).

Detecting alterations in hub genes. The cBio Cancer Genomics Portal (http://cbioportal.org), a public resource that provides a convenient interface for accessing the multidimensional cancer genomics and clinical data based on multiple platforms (35), was used to detect alterations in hub genes and to investigate the association between alterations and outcomes for patient.

Determiningalternative splicing ofhubgenes.TCGASpliceSeq (http://bioinformatics.mdanderson.org/TCGASpliceSeq) is a database that enables investigators to explore the alternative splicing events of various tumors based on TCGA data (36). In general, seven alternative splicing events were classified, including alternate donor (AD) sites, alternate terminators (ATs), alternate promoters (APs), alternate acceptor (AA) sites, exon skipping (ES), retained introns (RIs) and mutually exclusive exons (MEs) (37). Accordingly, the splicing events of the hub genes in HCC were extracted from TCGA SpliceSeq. Percent spliced in (PSI) values, an intuitive ratio for quantifying splicing events (38), were then compared between HCC and the normal tissues with Student's unpaired t-test using GraphPad Prism 7.04. 
Table I. Characteristics of the studies included in the meta-analysis.

\begin{tabular}{|c|c|c|c|c|c|c|}
\hline Author, year & Country & Series & Platform & HCC samples & Non-HCC samples & (Refs.) \\
\hline Li et al, 2008 & China & GSE10694 & GPL6542 & 78 & 88 & (89) \\
\hline Su et al, 2009 & China & GSE12717 & GPL7274 & 10 & 6 & (90) \\
\hline Burchard et al, 2010 & USA & GSE22058 & GPL10457 & 96 & 96 & (91) \\
\hline Sato et al, 2011 & Japan & GSE21362 & GPL10312 & 73 & 73 & $(92)$ \\
\hline Noh et al, 2013 & South Korea & GSE39678 & GPL15852 & 16 & 8 & (93) \\
\hline Wang et al, 2012 & USA & GSE31383 & GPL10122 & 9 & 10 & (94) \\
\hline Morita et al, 2016 & Japan & GSE41874 & GPL7722 & 3 & 4 & $(95)$ \\
\hline Shih et al, 2012 & Taiwan & GSE36915 & GPL8179 & 68 & 21 & (96) \\
\hline Wojcicka et al, 2014 & Poland & GSE63046 & GPL11154 & 24 & 24 & (97) \\
\hline Shen et al, 2014 & USA & GSE54751 & GPL18262 & 10 & 10 & (98) \\
\hline Lou et al, 2019 & Taiwan & GSE69580 & GPL10850 & 5 & 5 & (99) \\
\hline Murakami et al, 2015 & Japan & GSE57555 & GPL18044 & 5 & 16 & $(100)$ \\
\hline Ghosh et al, 2016 & India & GSE67882 & GPL10850 & 4 & 8 & $(101)$ \\
\hline Peng et al, 2015 & USA & GSE64632 & GPL18116 & 3 & 3 & $(102)$ \\
\hline Zhang et al, 2017 & China & GSE98269 & GPL20712 & 3 & 3 & $(103)$ \\
\hline Shi et al, 2018 & China & GSE115016 & GPL21572 & 12 & 12 & $(104)$ \\
\hline TCGA, 2018 & N/A & N/A & $\mathrm{N} / \mathrm{A}$ & 372 & 50 & - \\
\hline Chen et al, 2013 & China & N/A & $\mathrm{N} / \mathrm{A}$ & 15 & 15 & (12) \\
\hline
\end{tabular}

HCC, hepatocellular carcinoma; TCGA, The Cancer Genome Atlas; N/A, not available.

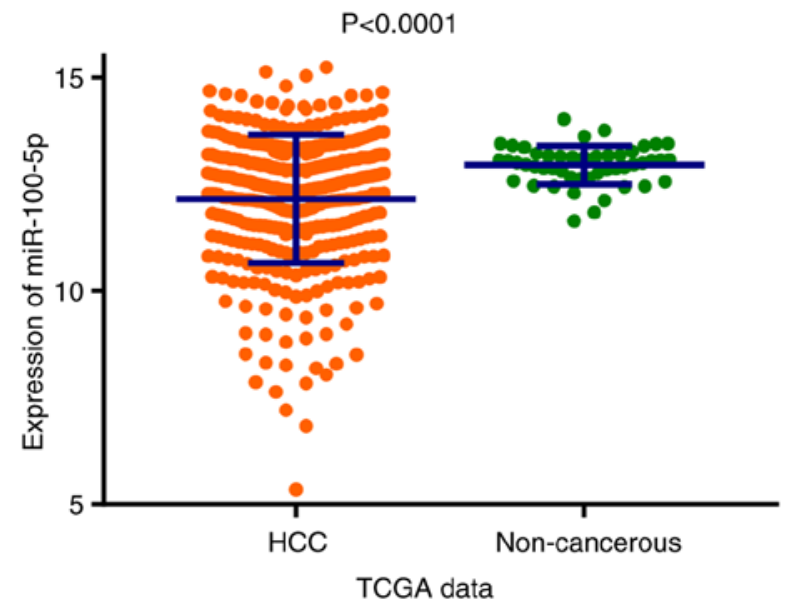

Figure 2. Expression of miR-100-5p was significantly decreased in the HCC group (372 samples) compared with the non-cancerous group (50 samples) from TCGA. miR, microRNA; HCC, hepatocellular carcinoma; TCGA, The Cancer Genome Atlas.

\section{Results}

Differences in the expression of miR-100-5p between groups. The scatter plot presented in Fig. 2 demonstrates that miR-100-5p expression was significantly reduced in the HCC group compared with the non-cancerous group based on TCGA data $(\mathrm{P}<0.0001)$. In total, there were 16 microarray datasets, one TCGA study and one published article (Table I), these included a total of 1,258 samples (806 HCC and 452 non-cancerous tissues) for the comprehensive meta-analysis (Fig. 3). The fixed effects model indicated that the pooled standard mean difference (SMD) was $-0.90(95 \%$ CI, -1.04 to $-0.77 ; \mathrm{I}^{2}, 66.0 \%$; $\left.<<0.001\right)$, while the pooled SMD was $-1.00\left(95 \% \mathrm{CI},-1.28\right.$ to $-0.72 ; \mathrm{I}^{2}, 66.0 \%$; $\left.\mathrm{P}<0.001\right)$ in the random effects model. Influence analysis revealed that two microarrays (GSE22058 and GSE21362), the TCGA data and one article may lead to heterogeneity. After removing the two microarrays (GSE22058 and GSE21362), the TCGA data and the article, the pooled SMD was -0.94 (95\% CI, -1.14 to $\left.-0.74 ; \mathrm{I}^{2}, 35.2 \% ; \mathrm{P}=0.093\right)$. It was determined that there was no publication bias by performing Begg's test $(\mathrm{P}=0.705)$ and Egger's test ( $\mathrm{P}=0.443$; Fig. 4). The meta-analysis indicated that the expression of miR-100-5p was significantly decreased in HCC tissue compared with non-cancerous tissue.

Clinical value of miR-100-5p in HCC with TCGA data. The association between the expression of miR-100-5p and the clinicopathological features of patients with $\mathrm{HCC}$ was investigated. The clinicopathological parameters of the patients with HCC are presented in Table II. Significance was determined for the following clinicopathological parameters: Age $(\mathrm{P}=0.049)$, tumor stage $(\mathrm{P}=0.022)$, tumor node metastasis $(\mathrm{TNM})$ stage $(\mathrm{P}=0.020)$, tumor grade $(\mathrm{P}<0.001)$, non-alcoholic fatty liver disease (NAFLD; $\mathrm{P}<0.001)$ and $\alpha$-fetoprotein (AFP) level $(\mathrm{P}<0.001)$. However, there was no statistical significance in liver cirrhosis, sex, lymph node stage, metastasis stage, Child-Pugh classification grade, hepatitis $\mathrm{B}$ virus or hepatitis $\mathrm{C}$ virus infection and alcohol consumption. Furthermore, survival analysis suggested that patients with HCC and lower expression levels of miR-100-5p exhibited significantly less favorable OS times $(\mathrm{P}=0.0003)$ compared with patients with higher expression levels of miR-100-5p (Fig. 5). The median survival of patients with high and low miR-100-5p expression 
A Study

$\%$

ID

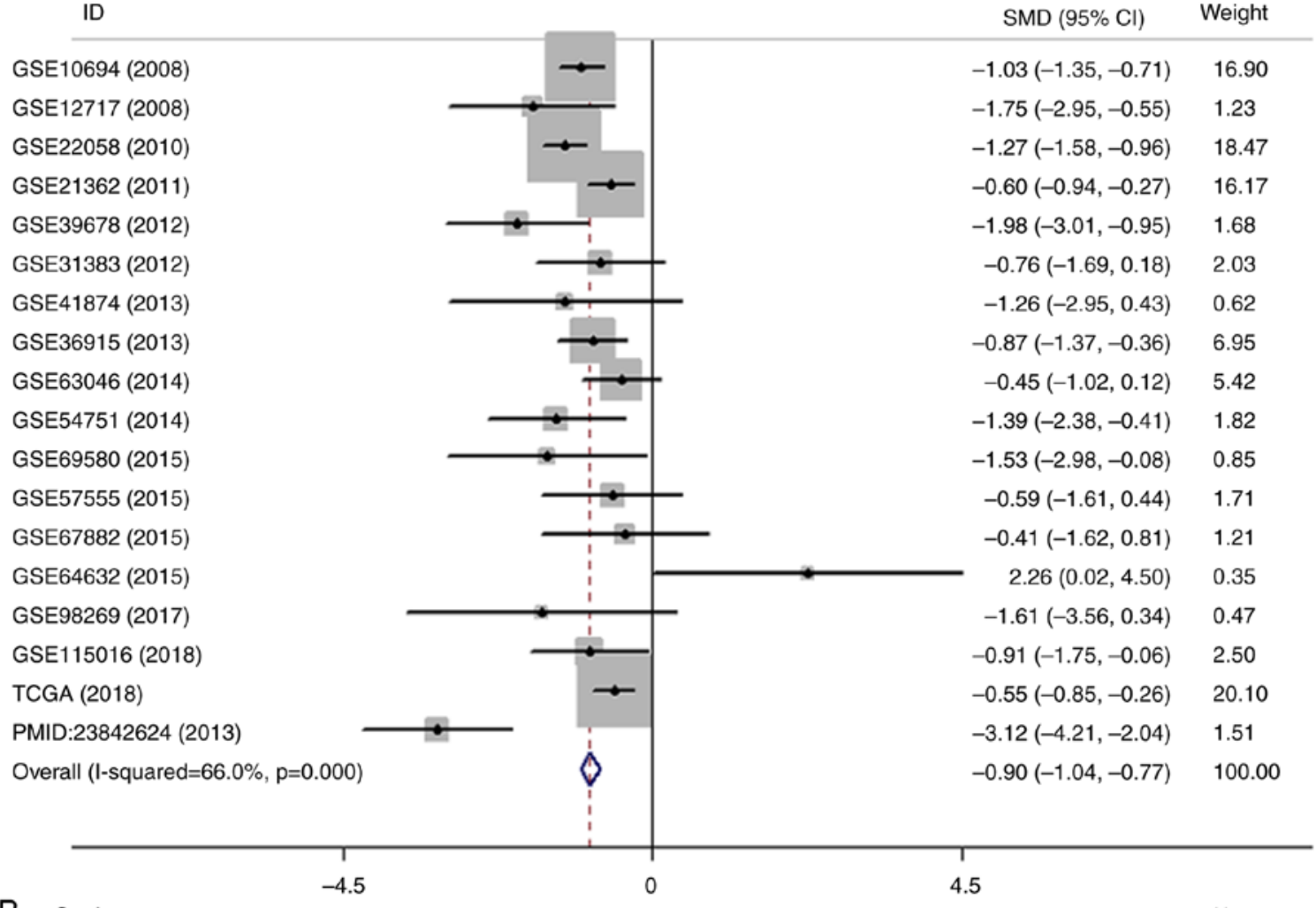

B Study

$\%$

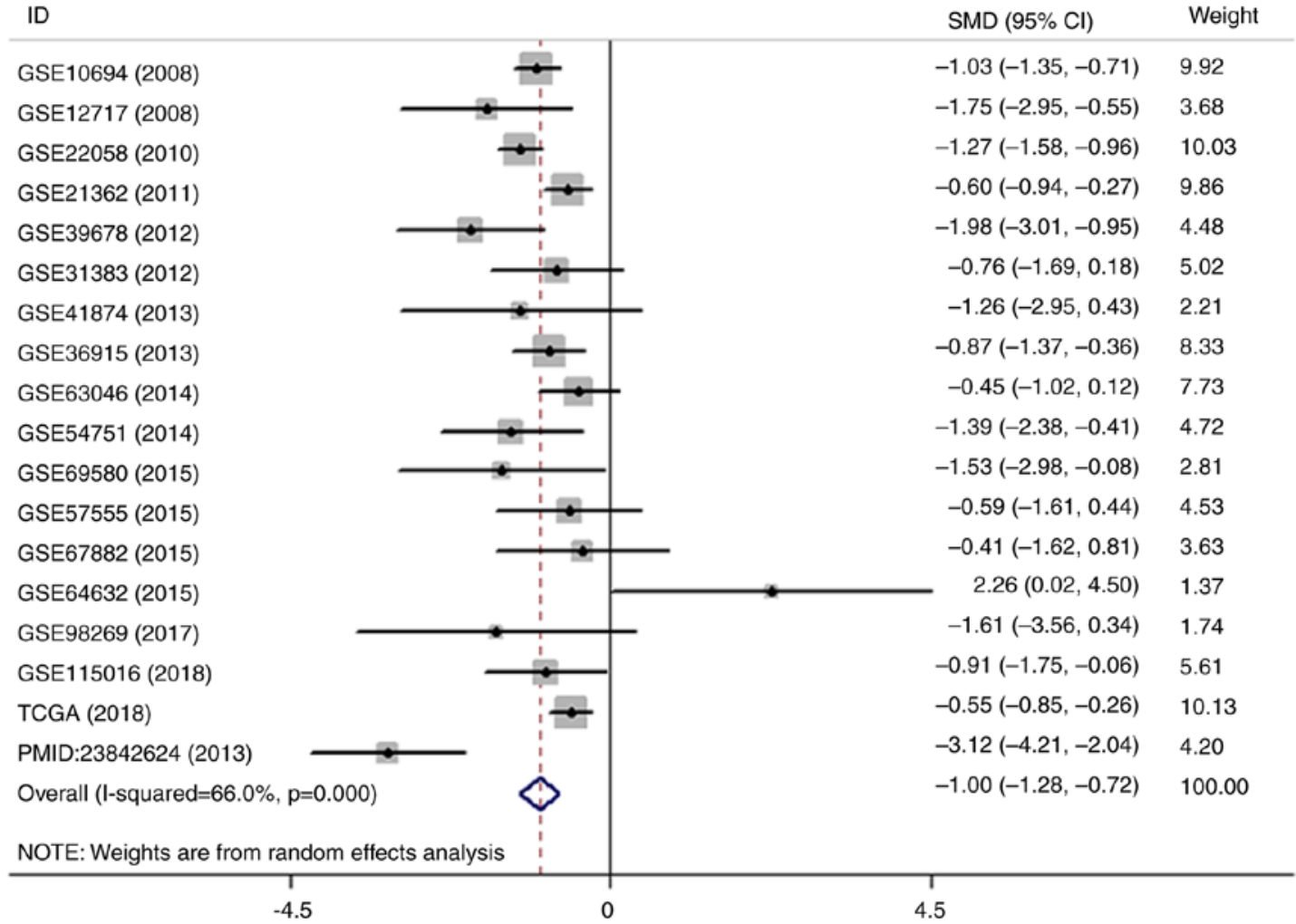

Figure 3. Meta-analysis of the differential expression of miR-100-5p in HCC and non-cancerous tissues. (A) Forest plot of miR-100-5p expression datasets from Gene Expression Omnibus, TCGA and an article. The fixed effects model indicated that the pooled SMD was $-0.90\left(95 \% \mathrm{CI},-1.04\right.$ to $-0.77 ; \mathrm{I}^{2}, 66.0 \% ; \mathrm{P}<0.001$. (B) Forest plot of the pooled SMD of miR-100-5p was -1.00 (95\% CI, -1.28 to $-0.72 ; \mathrm{I}^{2}, 66.0 \%$; P<0.001) using the random effects model.

were 2456 and 1372 days, respectively, indicating that miR-100-5p overexpression is associated with a better clinical outcome for patients with HCC.
Potential target genes of miR-100-5p. The target genes of miR-100-5p were identified using the following 12 target gene prediction platforms: miRWalk, miRanda, miRNAMap, 
C

Meta-analysis estimates, given named study is omitted

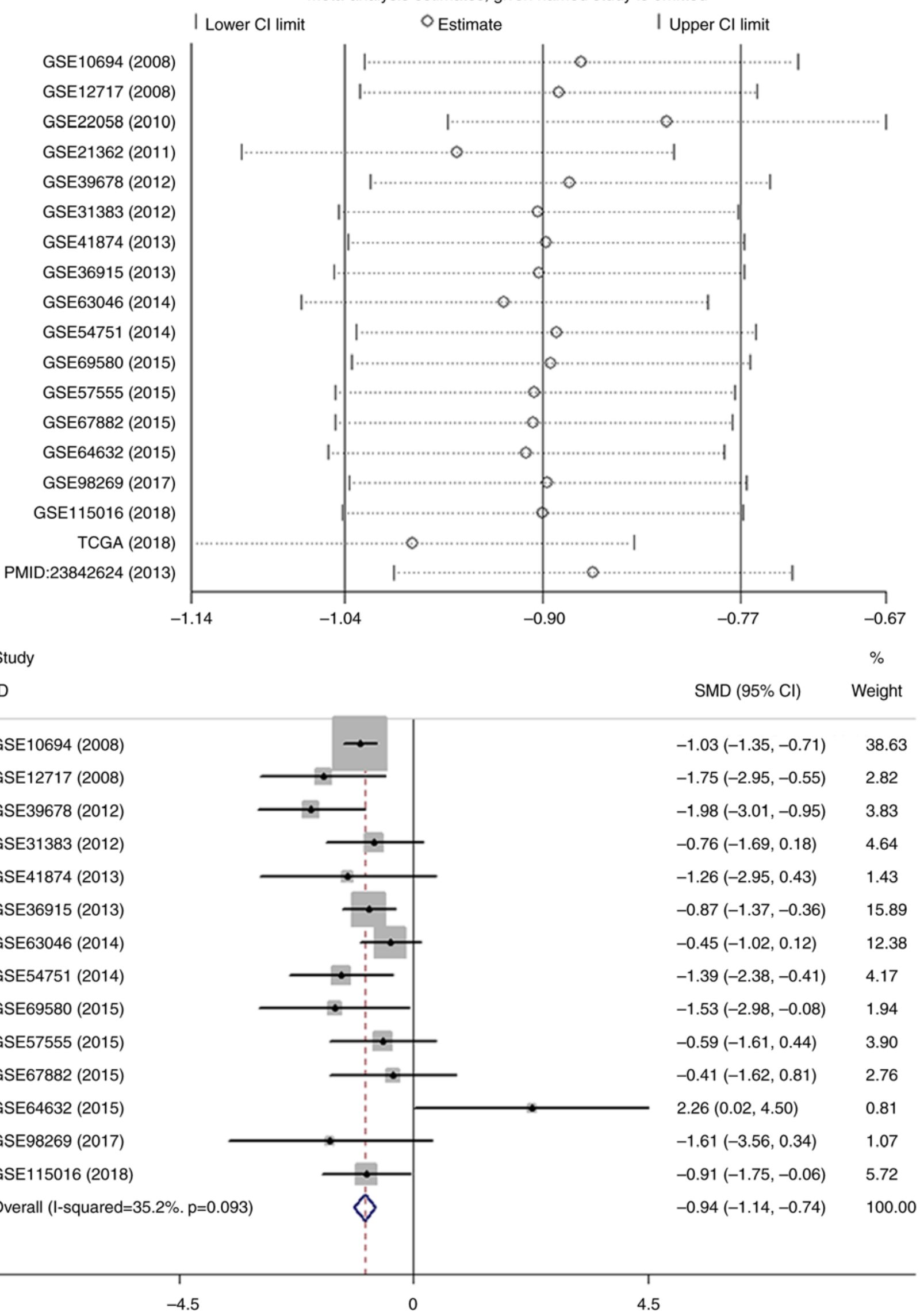

Figure 3. Continued. Meta-analysis of the differential expression of miR-100-5p in HCC and non-cancerous tissues. (C) Sensitivity analysis of the included studies. (D) Forest plot with the data leading to heterogeneity removed. The pooled SMD was $-0.94\left(95 \% \mathrm{CI},-1.14\right.$ to $\left.-0.74 ; \mathrm{I}^{2}, 35.2 ; \mathrm{P}=0.093\right)$. miR, microRNA; HCC, hepatocellular carcinoma; CGA, The Cancer Genome Atlas; SMD, standard mean difference; CI, confidence interval. 
Table II. Association of miR-100-5p expression and clinicopathological parameters in $\mathrm{HCC}$.

\begin{tabular}{|c|c|c|c|c|}
\hline Parameters & $\mathrm{n}$ & $\begin{array}{l}\text { niR-100-5p expression } \\
\left(2^{-\mathrm{ACq}}\right), \text { mean } \pm \text { SD }\end{array}$ & $\mathrm{t}$ & P-value \\
\hline \multicolumn{5}{|l|}{ Sex } \\
\hline Male & 253 & $12.2301 \pm 1.4228$ & 1.330 & 0.185 \\
\hline Female & 119 & $11.9950 \pm 1.6634$ & & \\
\hline \multicolumn{5}{|l|}{ Age, years } \\
\hline$<65$ & 222 & $12.0354 \pm 1.5341$ & -1.979 & 0.049 \\
\hline$\geq 65$ & 149 & $12.3490 \pm 1.4388$ & & \\
\hline \multicolumn{5}{|l|}{$\mathrm{T}$} \\
\hline $\mathrm{T} 1+\mathrm{T} 2$ & 276 & $12.2602 \pm 1.4053$ & 2.313 & 0.022 \\
\hline $\mathrm{T} 3+\mathrm{T} 4$ & 93 & $11.8000 \pm 1.7363$ & & \\
\hline \multicolumn{5}{|l|}{$\mathrm{N}$} \\
\hline YES & 4 & $10.9563 \pm 2.2066$ & 1.575 & 0.116 \\
\hline NO & 254 & $12.1331 \pm 1.4717$ & & \\
\hline \multicolumn{5}{|l|}{ M } \\
\hline YES & 4 & $12.1561 \pm 1.1603$ & -0.092 & 0.927 \\
\hline NO & 269 & $12.0859 \pm 1.5263$ & & \\
\hline \multicolumn{5}{|l|}{ Stage } \\
\hline $\mathrm{I}+\mathrm{II}$ & 258 & $12.2622 \pm 1.4063$ & 2.355 & 0.020 \\
\hline $\mathrm{III}+\mathrm{IV}$ & 90 & $11.7777 \pm 1.7662$ & & \\
\hline \multicolumn{5}{|l|}{ Grade } \\
\hline $\mathrm{G} 1+\mathrm{G} 2$ & 231 & $12.4402 \pm 1.4008$ & 4.964 & $<0.001$ \\
\hline $\mathrm{G} 3+\mathrm{G} 4$ & 137 & $11.6580 \pm 1.5585$ & & \\
\hline \multicolumn{5}{|l|}{ Child-Pugh } \\
\hline A & 220 & $12.2815 \pm 1.4836$ & -0.548 & 0.584 \\
\hline $\mathrm{B}+\mathrm{C}$ & 22 & $12.4645 \pm 1.6079$ & & \\
\hline \multicolumn{5}{|l|}{$\mathrm{HBV} / \mathrm{HCV}$} \\
\hline YES & 156 & $12.2373 \pm 1.4439$ & -0.530 & 0.596 \\
\hline NO & 197 & $12.1527 \pm 1.5251$ & & \\
\hline \multicolumn{5}{|l|}{ Alcohol } \\
\hline YES & 117 & $12.2012 \pm 1.4718$ & 0.098 & 0.922 \\
\hline NO & 236 & $12.1846 \pm 1.4994$ & & \\
\hline \multicolumn{5}{|l|}{ NAFLD } \\
\hline YES & 19 & $12.9891 \pm 0.6046$ & 5.229 & $<0.001$ \\
\hline NO & 334 & $12.1447 \pm 1.5110$ & & \\
\hline \multicolumn{5}{|l|}{$\operatorname{AFP}(\mathrm{ng} / \mathrm{ml})$} \\
\hline$<400$ & 216 & $12.3754 \pm 1.4072$ & 4.071 & $<0.001$ \\
\hline$\geq 400$ & 65 & $11.3984 \pm 1.7744$ & & \\
\hline \multicolumn{5}{|l|}{ Cirrhosis } \\
\hline YES & 80 & $12.3822 \pm 1.3630$ & -0.568 & 0.571 \\
\hline NO & 135 & $12.2631 \pm 1.5524$ & & \\
\hline
\end{tabular}

HBV, hepatitis B; HCV, hepatitis C; NAFLD, non-alcoholic fatty liver disease; AFP, $\alpha$-fetoprotein.

Microt4, miRBridge, PicTar, PITA, miRMap, miRDB, RNAhybrid, RNA22 and TargetScan. In total, 447 candidate hub genes (Table SI) for miR-100-5p were predicted by at least 4 of the 12 online platforms used in the present study.
GO annotation and KEGG pathway. GO and KEGG annotation of the 447 potential hub genes of miR-100-5p was conducted using the online platform DAVID. GO annotation revealed that a total of 99 terms were significantly enriched $(\mathrm{P}<0.05)$ through the candidate genes identified. KEGG analysis identified four signaling pathways that were significantly enriched. The top 10 enriched GO terms and the significant KEGG pathways, which may contribute to targeted therapy for patients with HCC, are presented in Fig. 6. GO annotation showed that the three most significant terms for biological processes (BPs) were 'regulation of transcription', 'transcription', and 'negative regulation of transcription, DNA-dependent' (Fig. 6B). For cellular components (CCs), the candidate genes most significantly enriched were 'chromatin remodeling complex', 'membrane fraction' and 'plasma membrane part' (Fig. 6C). In molecular functions (MFs), 'transcription regulator activity', 'DNA binding' and 'ion binding' were the terms most commonly associated with the target genes (Fig. 6D). The two most significant KEGG pathways identified were involved in cancer and heparan sulfate biosynthesis (Fig. 6A).

PPI network analysis. A PPI network was constructed, consisting of 158 nodes and 229 lines, by inputting a total of 447 potential target genes into String App (Fig. 7). Each protein may interact with multiple proteins, which may form the underlying molecular regulatory mechanism of miR-100-5p in HCC. In total, the following 6 hub genes were identified based on a degree $>7$ in the PPI network: Histone deacetylase (HDAC) 2, HDAC3, SHC transforming protein 1 (SHC1), RAC1, IGF1R and E3-unbiqitin protein ligase CBL (CBL). The six key genes may exert an important function in the regulatory mechanism of miR-100-5p in HCC.

Spearman correlation analysis. Spearman correlation analysis revealed that HDAC2 $(r=-0.3878 ; \mathrm{P}<0.0001)$, HDAC3 $(r=-0.1816 ; \mathrm{P}=0.0005), \mathrm{SHC} 1(\mathrm{r}=-0.2894 ; \mathrm{P}<0.0001), \mathrm{RAC} 1$ $(r=-0.386 ; \mathrm{P}<0.0001)$ and $\mathrm{CBL}(\mathrm{r}=-0.1259 ; \mathrm{P}=0.0158)$ were inversely associated with miR-100-5p expression. IGF1R $(\mathrm{r}=-0.0876 ; \mathrm{P}=0.0936)$ exhibited a trend towards negative correlation with miR-100-5p expression, although this was not statistically significant (Fig. 8).

Protein levels of hub genes. The protein levels of HDAC2 (antibody, CAB005054), HDAC3 (antibody, CAB005583), SHC1 (antibody, CAB016305), RAC1 (antibody, CAB035994), IGF1R (antibody, CAB010268) and CBL (antibody, HPA027956) in HCC and noncancerous tissue were obtained from the Human Protein Atlas database. As presented in Fig. 9, HDAC2, HDAC3, SHC1 and IGF1R exhibited high staining and strong intensity in HCC. RAC1 and CBL exhibited medium staining and an average intensity in HCC. However, in normal liver tissue, IGF1R and SHC1 exhibited moderate and low staining, respectively. The protein expression levels of HDAC2, HDAC3, RAC1 and CBL were below the limit of detection in normal liver tissue.

Expression and prognostic significance of hub genes. Of the 6 hub genes, 4 genes (HDAC2, HDAC3, SHC1 and RAC1) exhibited overexpression according to Roessler's dataset and Chen's dataset from the GEO database. As shown in Fig. 10A and B, the expression 
A Begg's funnel plot with pseudo $95 \%$ confidence limits

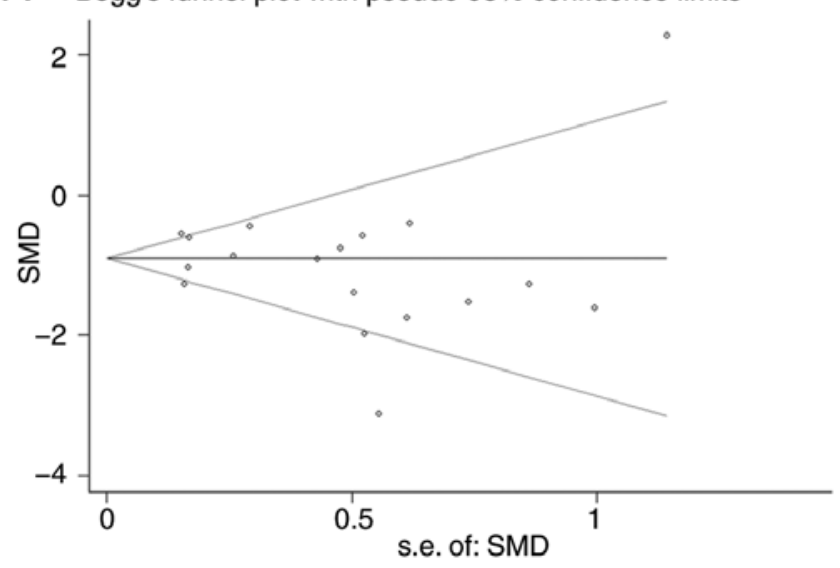

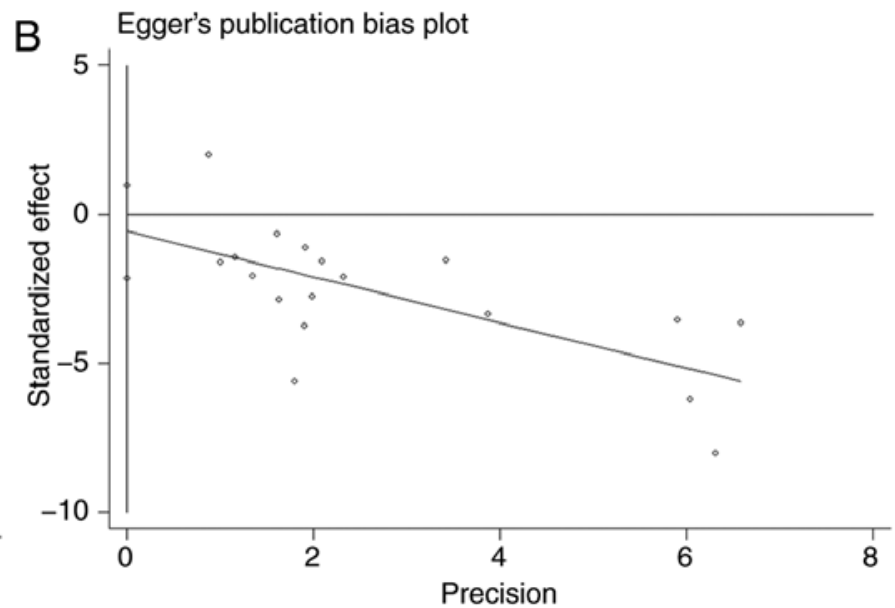

Figure 4. Determination of publication bias. No significant publication bias was found using $(\mathrm{A}) \mathrm{Begg}$ 's test $(\mathrm{P}=0.705)$ or $(\mathrm{B}) \mathrm{Egger}$ 's test $(\mathrm{P}=0.443)$. s.e., standard error; SMD, standard mean difference.

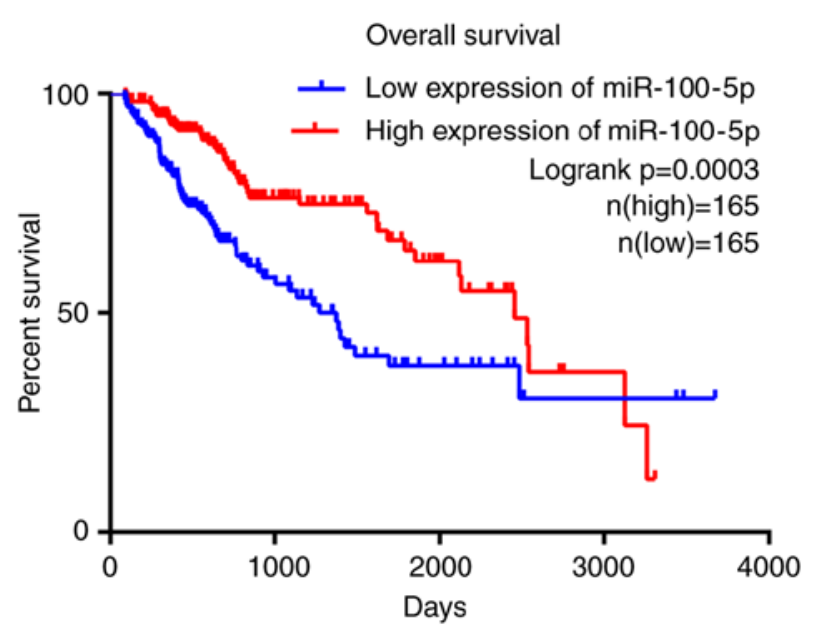

Figure 5. Prognosis value of miR-100-5p. The association between miR-100-5p expression and overall survival of patients with hepatocellular carcinoma based on The Cancer Genome Atlas cohort $(\mathrm{P}=0.0003)$. miR, microRNA.

levels of HDAC2 in both Roessler's dataset $\left[\mathrm{P}=4.21 \times 10^{-46}\right.$; fold change (FC), 1.806] and Chen's dataset $(\mathrm{P}=0.007$; FC, 1.191) were significantly upregulated in HCC tissue compared with the normal liver tissue. The expression of HDAC3 in Chen's dataset was significantly higher in HCC tissues compared with the normal liver tissue (Fig. 10C; $\mathrm{P}=1.24 \times 10^{-6} ; \mathrm{FC}, 1.314$ ). The expression of RAC1 ( $\left.\mathrm{P}=7.91 \times 10^{-46} ; \mathrm{FC}, 1.422\right)$ and $\mathrm{SHC} 1\left(\mathrm{P}=4.91 \times 10^{-25} ; \mathrm{FC}\right.$, 1.613) in Roessler's dataset were significantly increased in $\mathrm{HCC}$ tissues compared with the normal liver tissue (Fig. 10D and E). As miR-100-5p is downregulated in HCC, the genes with increased expression in HCC are potential target genes of miR-100-5p. As presented in Fig. 11, it was found that higher expression levels of HDAC2 (HR, 1.910; 95\% CI, 1.309-2.787; P=0.0007), HDAC3 (HR, 1.474; 95\% CI, 1.012-2.146; $\mathrm{P}=0.0435)$, SHC1 (HR, 1.52; 95\% CI, 1.043-2.215; $\mathrm{P}=0.0281)$ and $\mathrm{RACl}(\mathrm{HR}, 1.817 ; 95 \% \mathrm{CI}$, $1.248-2.645 ; \mathrm{P}=0.0022)$ were significantly associated with worse OS.

Alterations of hub genes. Gene alteration analysis of the 6 hub genes in the 360 TCGA patients were analyzed using the cBioPortal database, this analysis indicated that the main types of gene alteration were mRNA upregulation and amplification. In total 7, 11, 21, 12, 11 and $6 \%$ of cases had genetic alterations in HDAC2, HDAC3, SHC1, RAC1, IGF1R and CBL, respectively (Fig. S1). The alterations in HDAC2 $(\log \operatorname{rank} \mathrm{P}=0.0213), \mathrm{SHC} 1\left(\log \operatorname{rank} \mathrm{P}=6.153 \times 10^{-3}\right)$ and RAC1 $(\log$ rank $\mathrm{P}=0.0144)$ were associated with a poorer OS in patients with HCC from the TCGA dataset, while the alterations that occurred in HDAC3, IGF1R and CBL were not significantly associated with OS (Fig. S2). The changes in HDAC2 $\left(\log\right.$ rank $\left.\mathrm{P}=6.488 \times 10^{-3}\right)$, SHC1 $(\log$ rank $\mathrm{P}=0.0347)$ and $\mathrm{IGF} 1 \mathrm{R}\left(\log \operatorname{rank} \mathrm{P}=6.991 \times 10^{-3}\right)$ were associated with unfavorable disease-free survival (DFS) in patients with HCC from the TCGA dataset, whereas alterations in HDAC3, RAC1 and CBL were not significantly associated with DFS (Fig. S3).

Alternative splicing of hub genes. In total, the splicing events of 4 genes (HDAC2, HDAC3, SHC1 and RAC1) were analyzed. To define a splicing event accurately, each splicing event was named with a unique code in the present study. For example, for the code SHC1-7856-AA, SHC1 is the gene symbol, 7856 denotes the order number of the splicing event in the dataset and AA indicates the type of splicing. The results showed that alternative splicing event SHC1-7856-AA was significantly decreased in HCC $(\mathrm{P}<0.0001)$, while RAC1-78720-ES was significantly increased ( $\mathrm{P}=0.0253$; Fig. S4). However, no statistically significant alternative splicing events were identified in HDAC2 and HDAC3 ( $>>0.05)$. These findings may facilitate the understanding of the potential molecular mechanisms of the target genes.

\section{Discussion}

HCC is the most common type of primary liver cancer (1); however, predicting the outcome for patients remains a challenge. Identifying prospective biomarkers and understanding the underlying mechanisms of HCC may provide novel therapeutic, prognostic and monitoring strategies for HCC. The present study aimed to identify hub genes and signaling pathways regulated by miR-100-5p, and 


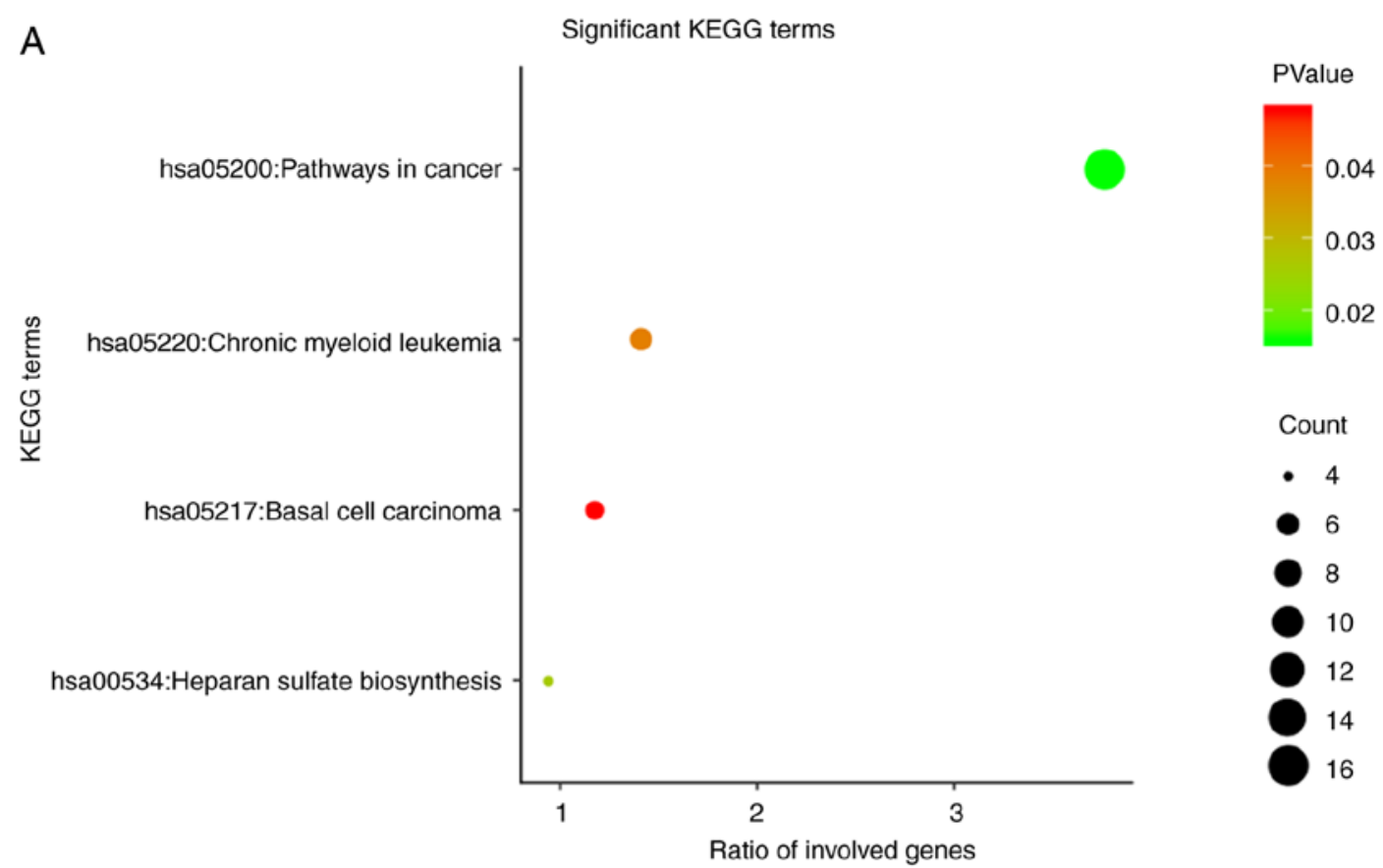

B Top 10 significant BP terms

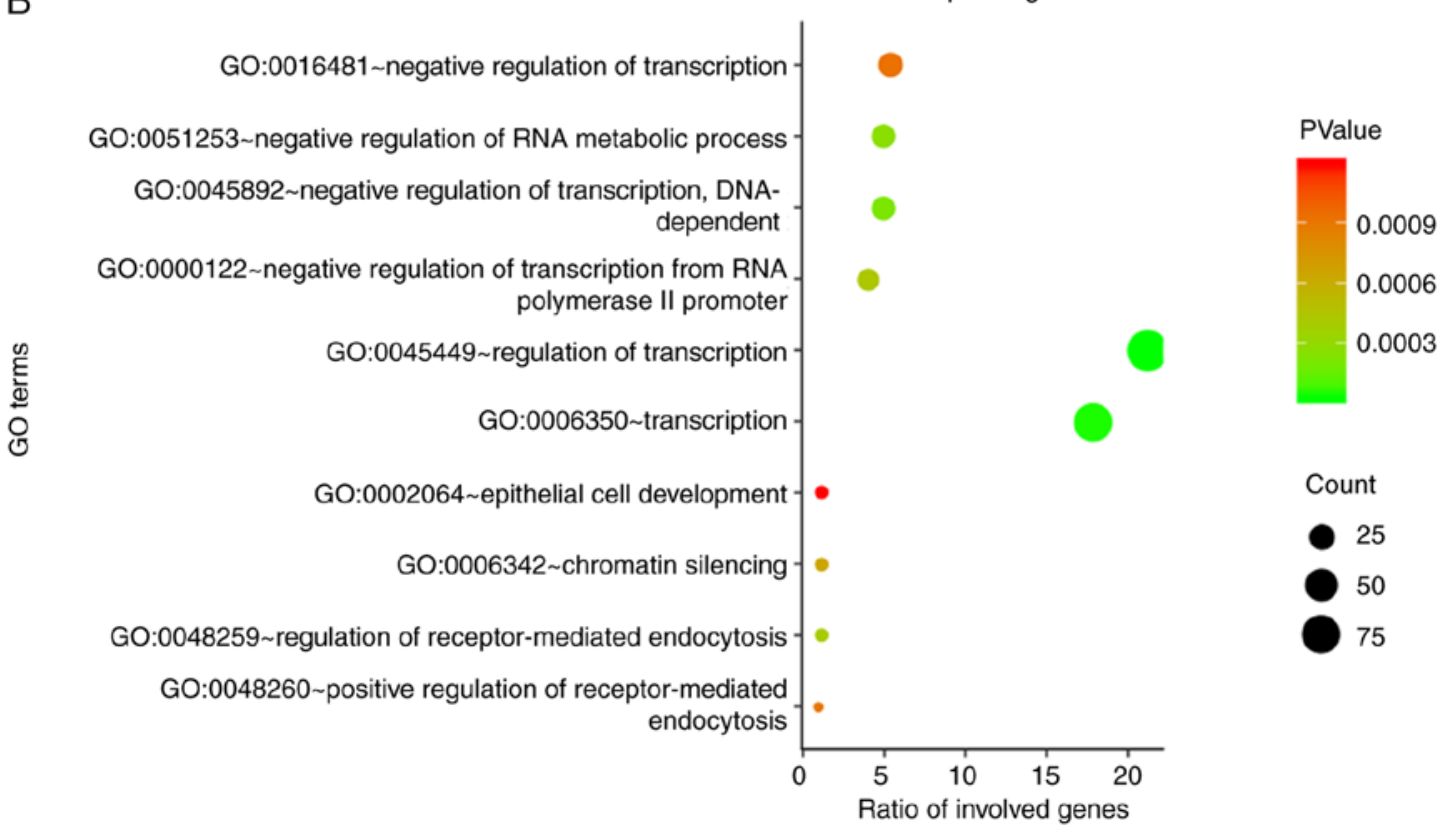

Figure 6. GO and KEGG analysis of microRNA-100-5p. (A) In total, 4 significant KEGG pathways were identified. The top 10 significant GO terms in (B) biological processes.

to elucidate the role of this miRNA in HCC. It has been reported that miR-100-5p functions in diverse human cancers. For example, previous studies reported that miR-100-5p could reverse cisplatin resistance in breast cancer, lung cancer and ovarian cancer (9,39-41). Previous studies have also reported that miR-100 may influence the metastatic potential of various cancers, including prostate cancer, gastric cancer and nasopharyngeal carcinoma $(10,11,42,43)$. It has been proposed that high levels of miR-100-5p are associated with a longer survival time in patients with various types of cancer, including glioblastoma and epithelial ovarian cancer $(44,45)$. In two studies by Zhou et al $(13,14)$, miR-100-5p was found to target mTOR and block the mTOR-p70S6K signaling pathway in order to downregulate the protein level of angiopoietin 2, thus abrogating the vessels that encapsulated tumor cluster-dependent metastasis of hepatoma cells. The decreased expression of miR-100-5p can enhance ICMT-RAC1 signaling and promote the metastasis of HCC cells $(13,14)$. Furthermore, Ge et al (15) reported that miR-100-5p may reduce mTOR and IGF-1R levels by promoting the autophagy of hepatocellular carcinoma cells. A study by Petrelli et al (46) revealed that dysregulation of miR-100-5p was likely to be an early event in the development of hepatocarcinogenesis. However, the biological functions and mechanisms of miR-100-5p expression in HCC are still not completely understood. 
C

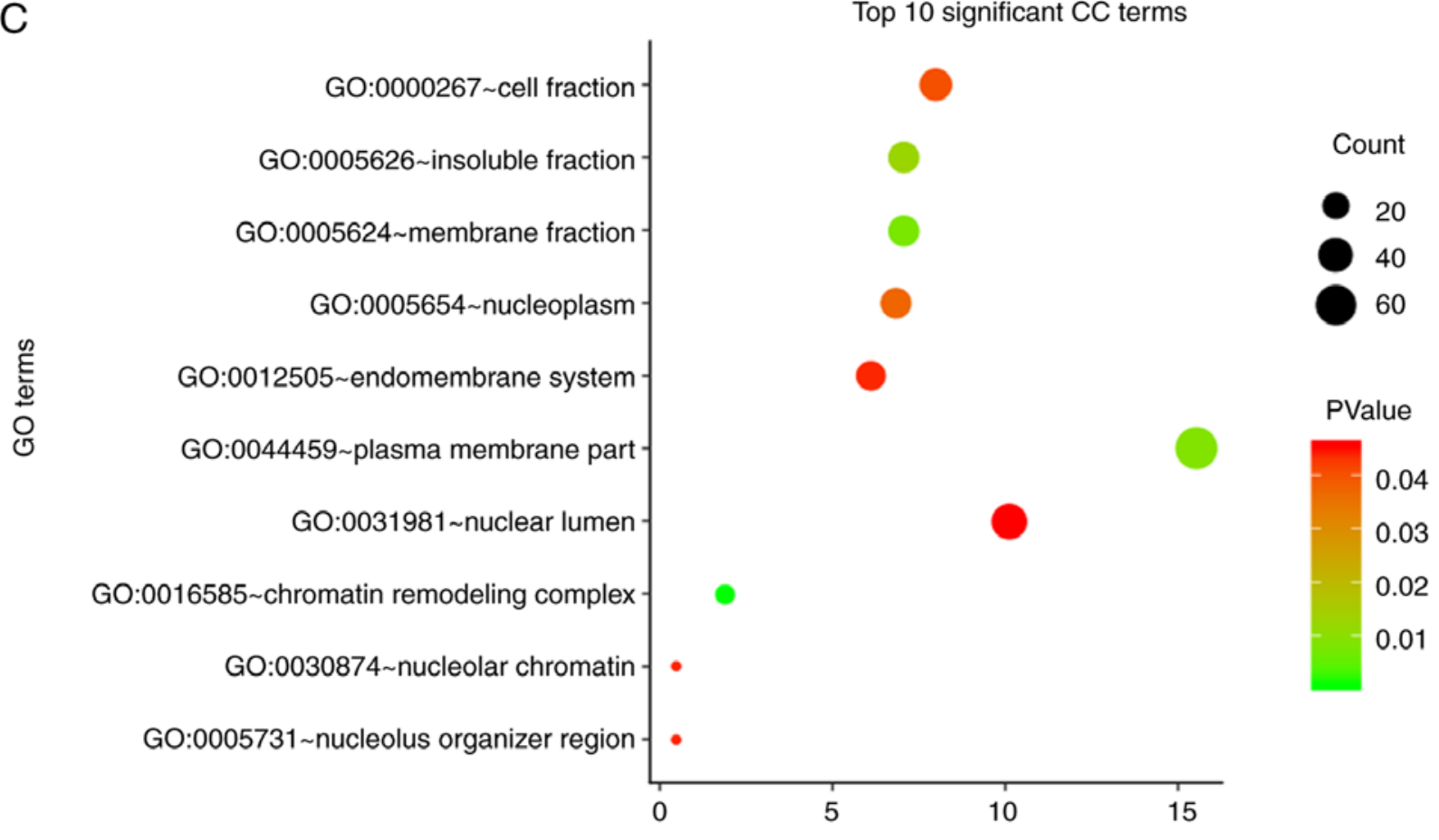

Top 10 significant CC terms

Ratio of involved genes
D

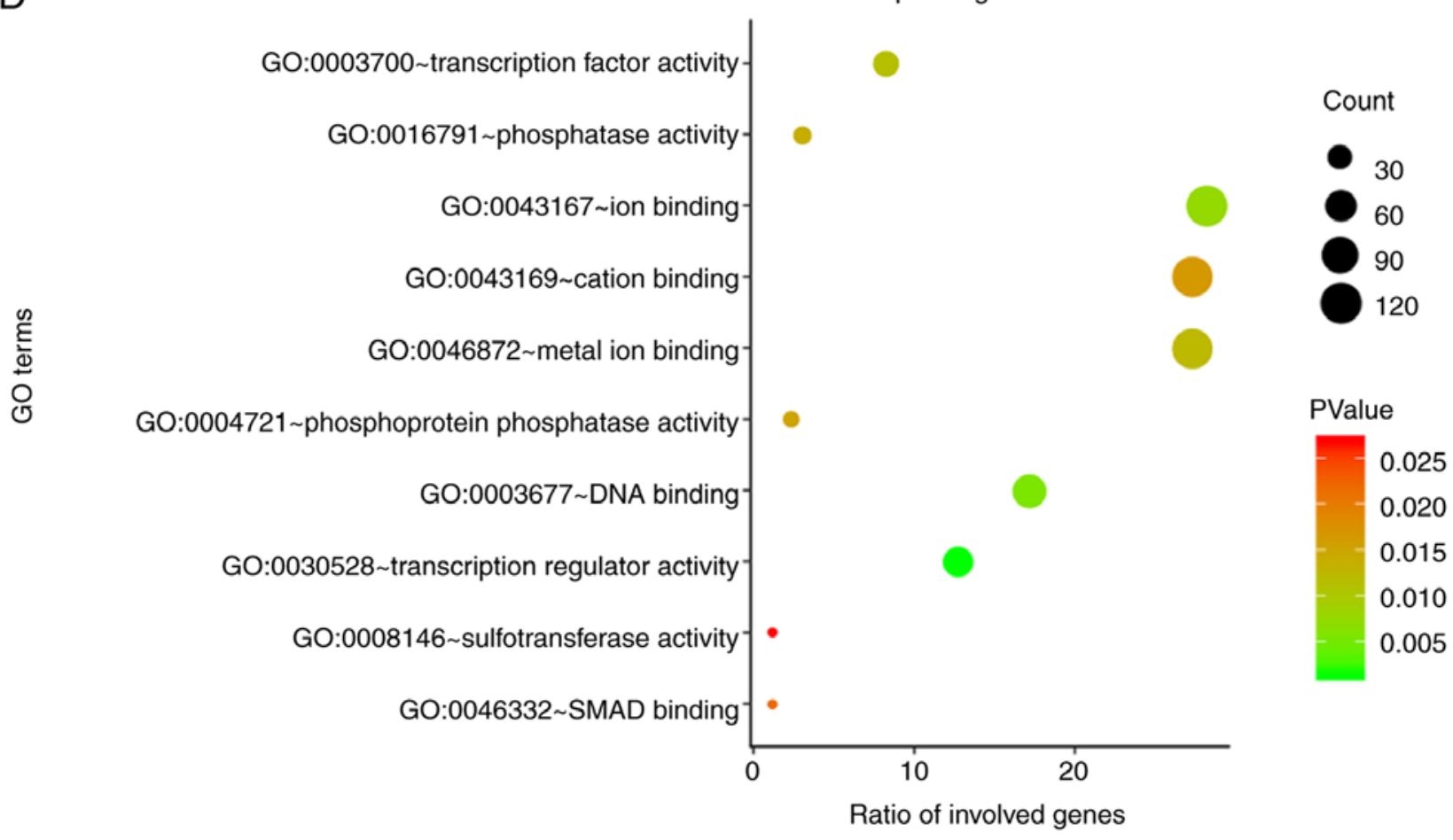

Figure 6. Continued. GO and KEGG analysis of microRNA-100-5p. (A) In total, 4 significant KEGG pathways were identified. The top 10 significant GO terms in (C) cellular components and (D) molecular functions. GO, Gene Ontology; KEGG, Kyoto Encyclopedia of Genes and Genomes.

To the best of our knowledge, only 3 studies $(12,13,46)$ have reported that the expression of miR-100-5p is decreased in HCC, with 2 of these 3 studies $(12,13)$ indicating that low expression of miR-100-5p is associated with clinicopathological features in patients with HCC. However, Varnholt et al (47) reported that the level of miR-100-5p was significantly increased in HCC tissues compared with normal tissues. Similarly, the upregulation of miR-100-5p in plasma or serum samples was demonstrated by Wang et al (48). As aforementioned, the expression of miR-100-5p in patents with HCC remains controversial. Therefore, the present study conducted a meta-analysis to understand whether miR-100-5p expression is decreased in HCC samples compared with its expression in non-HCC 

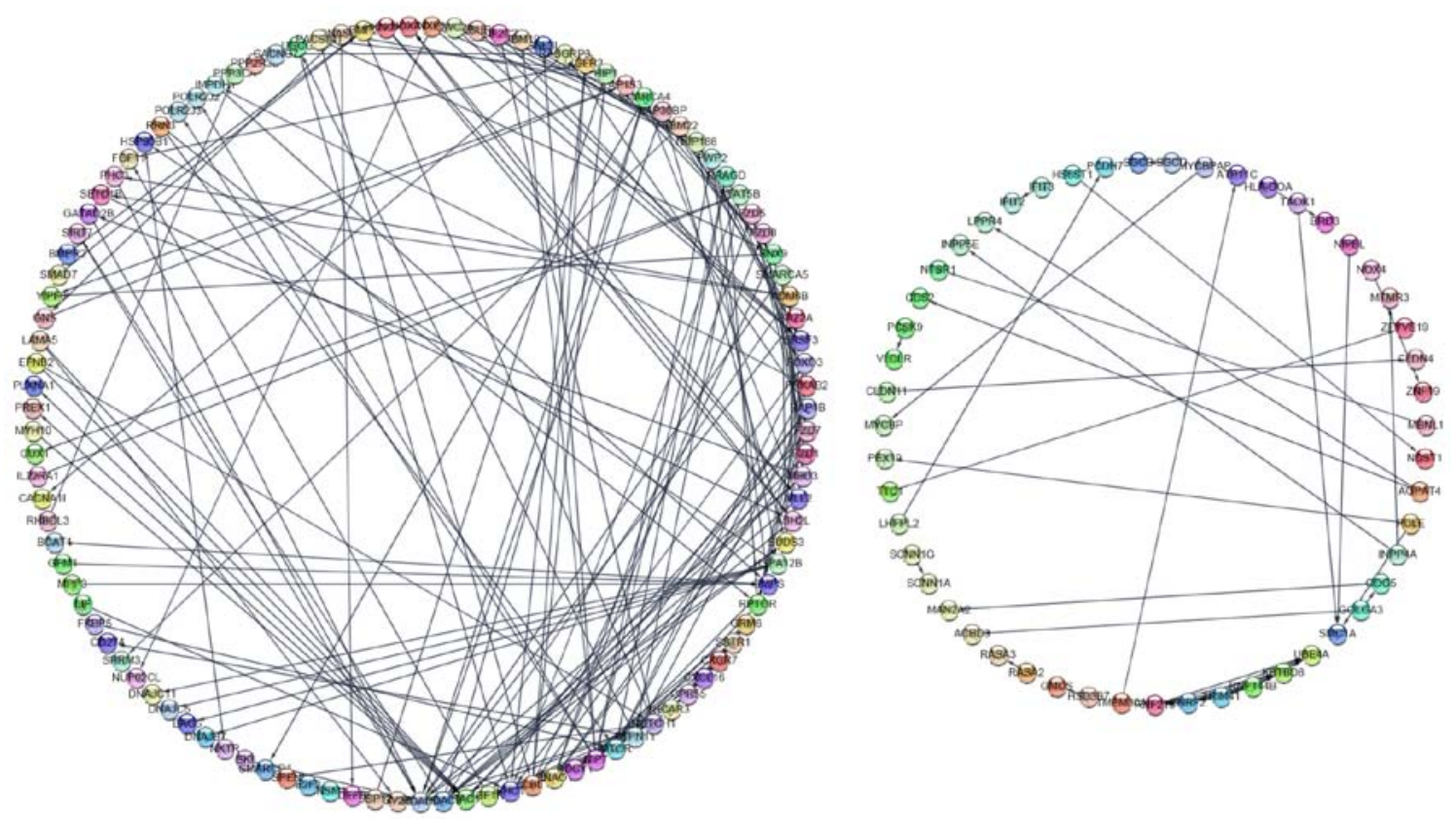

Figure 7. Protein-protein interaction network for the potential target genes of microRNA-100-5p. Each node denotes a gene product and lines represent the associations between gene products.
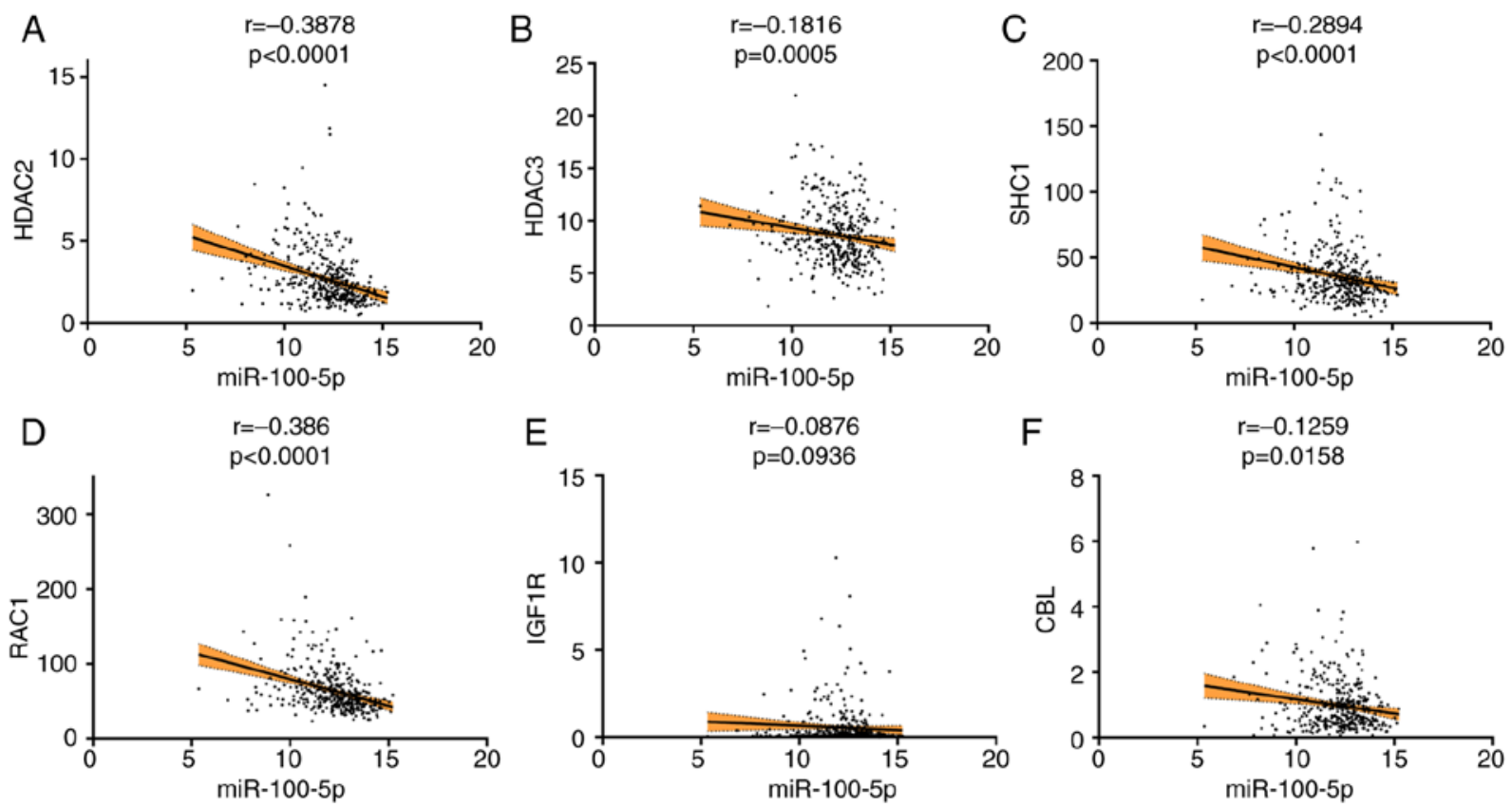

Figure 8. Spearman correlation analysis between miR-100-5p and potential target genes. (A) HDAC2 ( $r=-0.387 ; \mathrm{P}<0.0001)$; (B) HDAC3 ( $r=-0.1816 ; \mathrm{P}=0.0005)$; (C) SHC1 ( $r=-0.2894$; P<0.0001); (D) RAC1 ( $r=-0.386$; P<0.0001); (E) IGF1R ( $r=-0.0876 ; P=0.0936)$; and (F) CBL ( $r=-0.1259 ; P=0.0158)$. miR, microRNA; HDAC, histone deacetylate; SHC1, SHC-transforming protein 1; RAC1, Ras-related protein Rac1; IGF1R, insulin like growth factor 1 receptor; CBL, E3 ubiquitin-protein ligase CBL.

samples. In the present study, it was found that miR-100-5p was downregulated in HCC based on a total of 1,258 samples from TCGA, GEO and relevant articles. Reduced expression of miR-100-5p was associated with poorer OS and worse clinical parameters compared with normal miR-100-5p expression. Although the nature of the present study was similar to a study conducted by Chen et al (12), the findings of the present study were novel and provided further information as follows: i) The present study detected differences in the expression of miR-100-5p with a larger sample size (1,258 samples) based on the meta-analysis; ii) the present study suggested that miR-100-5p may be used to predict the progression of HCC due to the close associated between miR-100-5p expression and clinicopathological features, including age, tumor stage, TNM stage, tumor grade, NAFL and AFP level; and iii) the results of the current study suggested that miR-100-5p may serve as a reliable biomarker, with higher expression of miR-100-5p indicating a better 


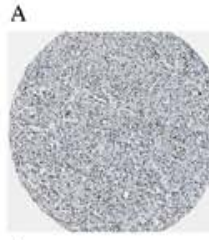

B

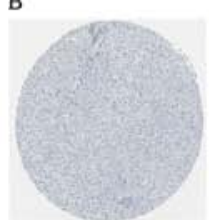

C
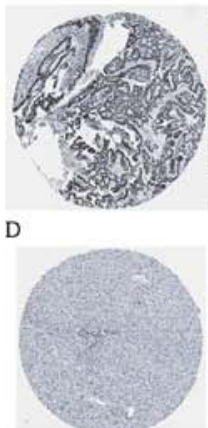

HDAC2 HCC

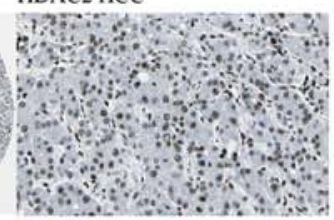

HDAC2 Normal

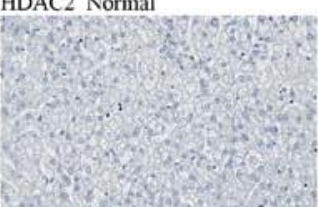

HDAC3 HCC

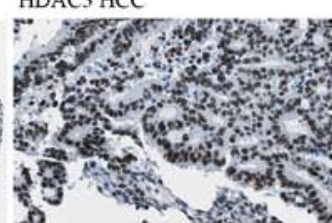

HDAC3 Normal

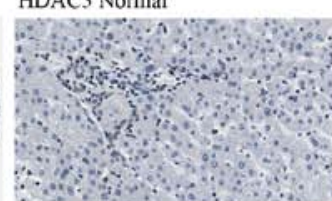

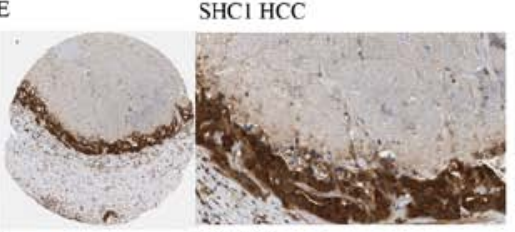

$\mathrm{F}$
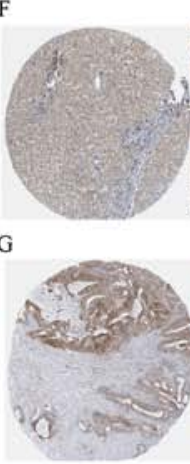

$\mathrm{H}$

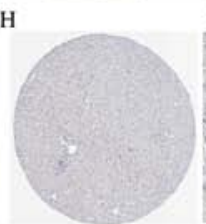

SHC1 Normal

$\mathrm{SHCl} \mathrm{HCC}$

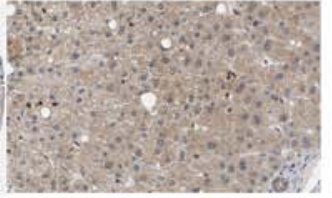

RACl HCC

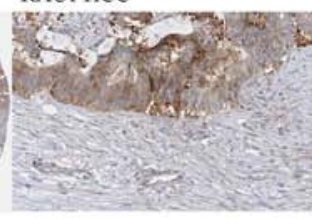

RACl Normal

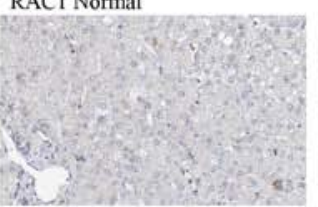

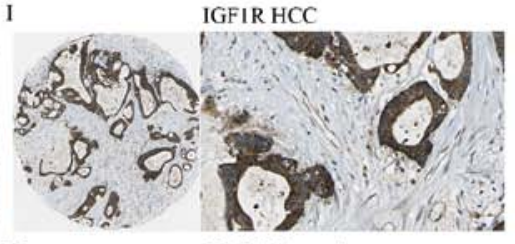

J

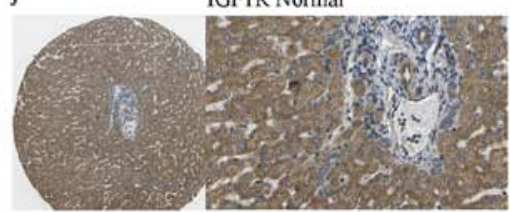

CBL HCC

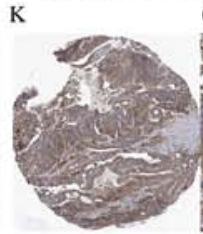

L

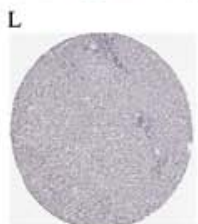

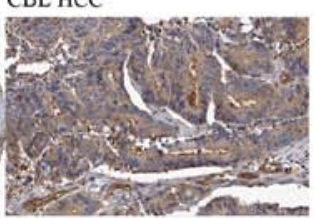

CBL Normal

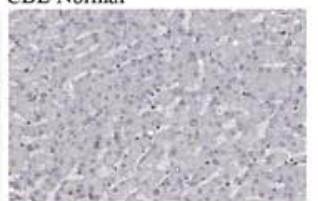

Figure 9. Immunohistochemical staining (magnification, $\mathrm{x} 40$ or $\mathrm{x} 400$ ) for protein expression of the 6 hub genes of miR-100-5p. (A) High staining and strong intensity of HDAC2 in HCC (antibody, CAB005054). (B) Low expression of HDAC2 in normal liver tissue (antibody, CAB005054). (C) High staining and strong intensity of HDAC3 in HCC (antibody, CAB005583). (D) Low expression of HDAC3 in normal liver tissue (antibody, CAB005583). (E) High staining and strong intensity of SHC1 in HCC (antibody, CAB016305). (F) Low expression of SHC1 in normal liver tissue (antibody, CAB016305). (G) Medium staining and average intensity of RAC1 in HCC (antibody, CAB035994). (H) Low expression of RAC1 in normal liver tissue (antibody, CAB035994). (I) High staining and strong intensity of IGF1R in HCC (antibody, CAB010268). (J) Medium staining of IGF1R in normal liver tissue (antibody, CAB010268). (K) Medium staining and average intensity of CBL in HCC (antibody, HPA027956). (L) Low expression of CBL expression in normal liver tissue (antibody, HPA027956). HCC, hepatocellular carcinoma; miR, microRNA; HDAC, histone deacetylate; SHC1, SHC-transforming protein 1; RAC1, Ras-related protein Rac1; IGF1R, insulin like growth factor 1 receptor; CBL, E3 ubiquitin-protein ligase CBL.

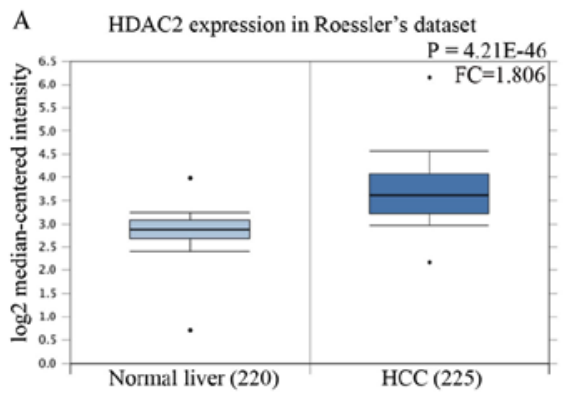

B

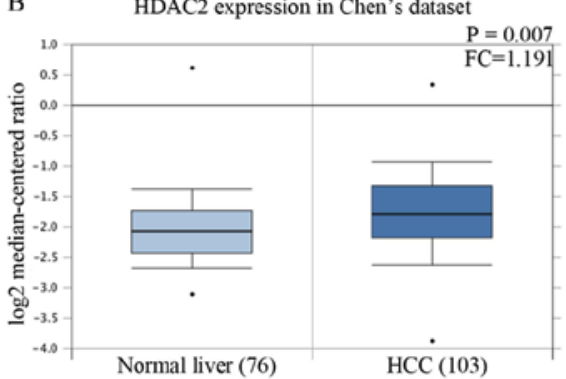

E $\quad \mathrm{SHCl}$ expression in Roessler's dataset

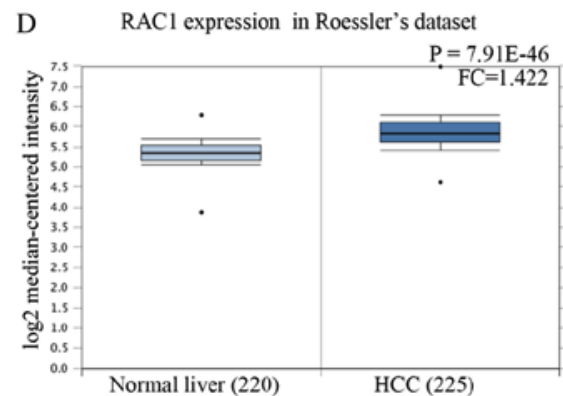

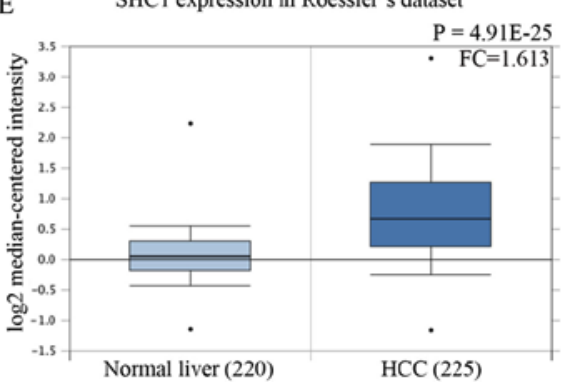

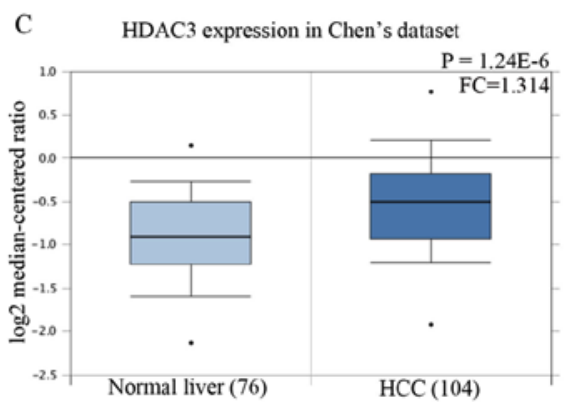

Figure 10. Expression of potential target genes from the Gene Expression Omnibus database. Expression of HDAC2 in (A) Roessler's dataset and (B) Chen's dataset. Expression of HDAC3 in (C) Chen's dataset. Expression of RAC1 in (D) Roessler's dataset. Expression of SHC1 in (E) Roessler's dataset. HDAC, histone deacetylate; SHC1, SHC-transforming protein 1; RAC1, Ras-related protein Rac1.

OS. Further investigations focusing on the association between miR-100-5p and HCC are required. In the present study bioinformatics analysis was performed to identify the potential molecular mechanisms of miR-100-5p in HCC. 
A

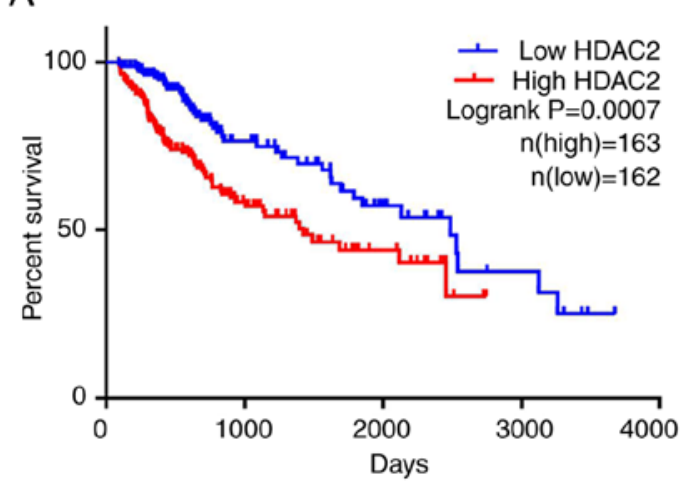

C

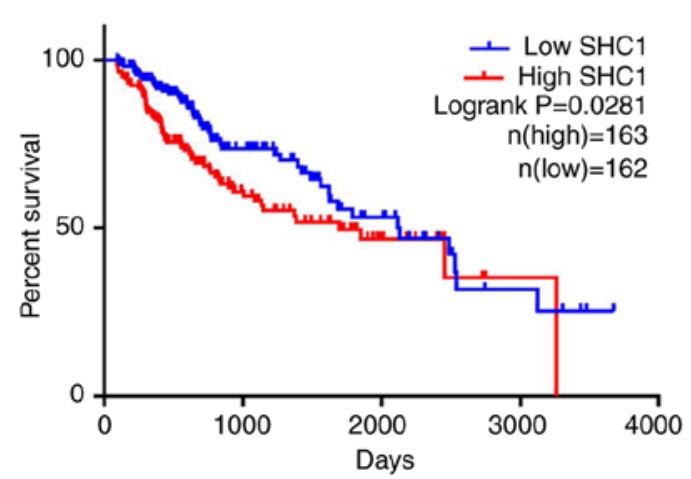

B

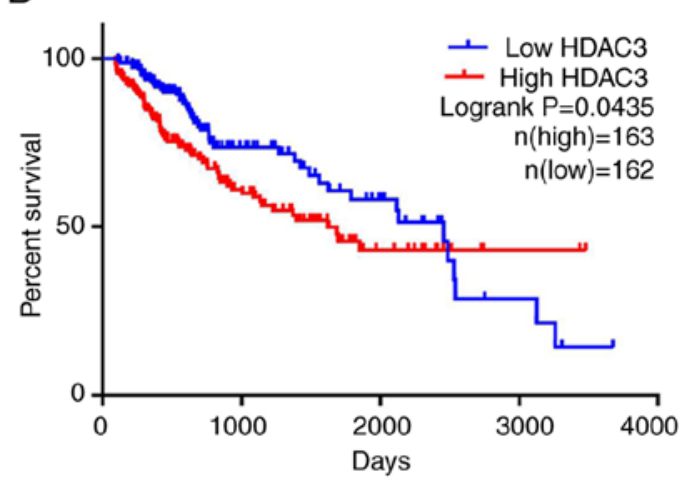

D

Overall survival

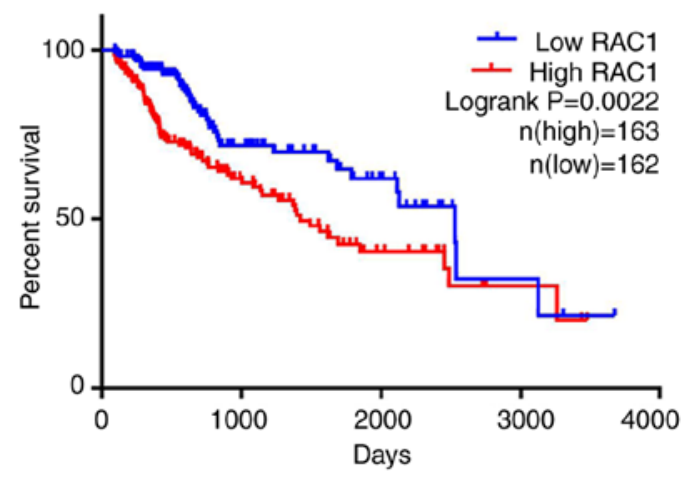

Figure 11. Association of hub gene expression and OS in patients with hepatocellular carcinoma using the Kaplan-Meier method based on The Cancer Genome Atlas cohort. (A) Association of HDAC2 (P=0.0007), (B) HDAC3 (P=0.0435), (C) SHC1 (P=0.0281) and (D) RAC1 (P=0.0022) expression and OS. OS, overall survival; HDAC, histone deacetylate; SHC1, SHC-transforming protein 1; RAC1, Ras-related protein Rac1.

For BPs, the top five related GO terms were 'regulation of transcription', 'transcription', 'negative regulation of transcription', 'regulation of receptor-mediated endocytosis' and 'DNA-dependent, negative regulation of RNA metabolic process'. For CCs, the top five statistically significant terms were 'chromatin remodeling complex', 'membrane fraction', 'plasma membrane part', 'insoluble fraction' and 'nucleoplasm'. For MFs, the top 5 terms were 'transcription regulator activity', 'transcription factor activity', 'DNA binding', 'ion binding' and 'metal ion binding'. These results suggest the target genes primarily functioned in transcriptional regulation by binding to chromatin, DNA or other biological molecules, thus affecting the occurrence and development of HCC. For the KEGG pathway analysis, the two most statistically significant pathways were 'pathways in cancer' and 'heparan sulfate biosynthesis'. Heparan sulfate is a linear polysaccharide that modulates numerous biological processes, including cell growth, angiogenesis and adhesion (49-51). A study by Cassinelli et al (52) found that the heparanase/heparan sulfate proteoglycan axis may be a potential novel therapeutic target in sarcomas. Ling et al (53) suggested that blocking heparan sulfate function in the heparin-binding domains of fibroblast growth factor receptor 1 inhibited growth of cancer cells. Dudás et al (54) showed that heparin and heparan sulfate may interfere with the function of topotecan in liver and liver cancer. Given these previous findings, it was hypothesized that miR-100-5p may exert a regulatory function on the biosynthesis of heparan sulfate, which may provide potential candidate targets for drug development in HCC. However, this should be verified in the future with experimental studies.

Additionally, 6 possible candidate genes, HDAC2, HDAC3, SHC1, RAC1, IGF1R and CBL, were identified by constructing a PPI network and were selected as they had a degree $>7$. The expression of HDAC2, HDAC3, SHC1 and RAC1 were significantly increased in $\mathrm{HCC}$ tissue compared with non-cancerous tissue. Survival analysis showed that the upregulation of HDAC2, HDAC3, SHC1 and RAC1 were associated with poorer outcome for patients with HCC.

The proteins encoded for by HDAC 2 and HDAC 3 belonged to the histone deacetylase family $(55,56)$. Previous studies have reported that these genes are involved in various BPs, such as cell cycle progression and transcriptional regulation (57-59). HDAC2 and HDAC3 have been found to be closely associated with the occurrence and survival rate in various cancer types, including colon cancer, breast cancer and HCC (60-64). The aforementioned studies also support the findings of the present study in which high expression of HDAC2 and HDAC3 was found to indicate a poorer prognosis for patients with HCC. To the best of our knowledge, the association between miR-100-5p and the two genes, HDAC 2 and HDAC3, has not previously been identified. In the present study it was reported that miR-100-5p is closely linked with HDAC2 and HDAC3, however, experiments should be performed to support these findings.

The gene encoding SHC1 encodes three main isoforms, including p66Shc, p52Shc and p46Shc. The p66Shc isoform may participate in modulating lifetime and the effects of reactive oxygen species (65). The other two isoforms, p52Shc 
and p46Shc, may be involved in the transforming activity of oncogenic tyrosine kinases $(66,67)$. Recently, various studies have found that this gene is closely related to a variety of cancer types. In one previous study, Zhang et al (68) found that p66Shc was highly expressed in colon cancer tissue, and knockdown of p66Shc in HCT8 cells reduced proliferation and accelerated apoptosis. A study by Yukimasa et al (69) also suggested that increased expression of p46Shc and p52Shc may be related to the occurrence of gastric cancer. In addition, Muniyan et al (70) reported that p66Shc was highly expressed in ovarian cancer cells compared with noncancerous cells, and that it may regulate the proliferation of human ovarian cancer cells. Furthermore, a previous study also identified that elevated expression of p66Shc was associated with the advance and metastasis of prostate cancer (71). At present, to the best of our knowledge, studies focusing on the regulatory mechanism of SHC1 in HCC are scarce. Yoshida et al (72) reported that the upregulation of SHC1 was closely associated with shorter survival in patients with HCC patients. In the present study, it was found that the expression of SHC1 was significantly increased in HCC tissue compared with non-cancerous tissue, and was closely associated with the outcome of patients with HCC. In the enriched GO terms, SHC1 was found to be strongly associated with 'regulation of cell proliferation', 'positive regulation of cellular biosynthetic process' and 'positive regulation of macromolecule biosynthetic process'. Therefore, it was hypothesized that miR-100-5p may target SHC1 to regulate cell proliferation and biosynthetic processes, thus contributing to the progression of HCC. However it is necessary to conduct experiments in vivo and in vitro to validate this hypothesis.

$\mathrm{RAC1}$ is important for a variety of cellular functions, including proliferation, adhesion, motility, migration and metastasis of tumor cells (73). Recently, Cheng et al (74) reported that RAC1 was upregulated in hypopharyngeal squamous cell carcinoma (HSCC) tissues, and that the silencing of $\mathrm{RACl}$ could reduce the invasion and migration abilities of HSCC cells. Consistently, the upregulation of RAC1 has been reported to be associated with poorer outcomes for patients with breast cancer (75). RAC1 inhibition may prevent metastasis and augment chemotherapy in gastric adenocarcinoma cells by blocking epithelial to mesenchymal transition (EMT) and cancer stem cell phenotypes (76). A previous study found that downregulation of miR-100-5p enhanced ICMT/RAC1 signaling and promoted the progression of HCC cells (13). In the present study, it was found that the expression of RAC1 was significantly higher in HCC tissue compared with normal tissue, and was inversely related to the expression of miR-100-5p. According to bioinformatics analysis, RAC1 was enriched in various BPs, such as 'regulation of receptor-mediated endocytosis', 'cell morphogenesis', 'cellular component morphogenesis' and 'epithelial cell differentiation'. These BPs play important roles in the growth, migration and differentiation of tumor cells, thereby contributing to the occurrence and development of cancer (77-80). Additionally, the data in the present study revealed that the upregulation of RAC1 was associated with poorer OS in patients with HCC. Therefore, it was hypothesized that the miR-100-5p/RAC1 signaling pathway may be important in the metastasis of HCC, and hence, may influence prognosis of patients with HCC. This indicates that interfering with the miR-100-5p/RAC1 signaling pathway may provide a novel treatment strategy for HCC. Nevertheless, further studies are required to support this hypothesis.

A number of previous studies have suggested that genetic alterations may affect the occurrence and progression of tumor (81-83). Jonckheere et al (84) reported that K-RAS mutation was the earliest genetic alteration occurring in pancreatic ductal adenocarcinoma, which could alter the expression of miRNA. In the present study, alterations in 6 key hub genes (HDAC2, HDAC3, SHC1, RAC1, IGF1R and CBL) were identified. The main alterations identified in the hub genes were amplification and mRNA upregulation. Alterations in HDAC2, SHC1, RAC1 and IGF1R were closely associated with a poorer outcome for patients with HCC. It is anticipated that these genetic alterations may be associated with the downregulation of miR-100-5p, thus playing an important role in the progression of HCC. However, further studies are required.

Alternative splicing is a common mechanism for gene regulation in humans, and it plays an important role in tumorigenesis, progression and therapy $(85,86)$. Generally, miRNAs work by binding to the 3'untranslated regions (UTRs) of their target genes (87). However, other functions of miRNAs are being identified. For example, Teplyuk et al (88) revealed that miR-10b can modulate the splicing events of its target genes by binding to 5'UTRs in intracranial glioblastoma (88). In the present study, it was found that the splicing events SHC1-7856-AA and RAC1-78720-ES were significantly decreased and increased in HCC compared with normal tissue, respectively, which may indicate that miR-100-5p is associated with alternative splicing of SHC1 and RAC1. Overall, the mechanism of how miR-100-5p influences its target genes warrants further study.

Although the results of the present study suggest that miR-100-5p may function as a tumor suppressor and be a valuable prognostic biomarker for HCC, it should be emphasized that several limitations exist in the present study. As only one previous study (48) involving serum samples could be found, no meta-analysis on circulating miRNAs could be performed. The current study therefore was unable to provide a minimally invasive method and early prognostic indicator for patients with HCC. The sample population for the clinical parameters was small, despite being larger than previous studies, which was likely to limit the stability of results. In order to comprehensively explore the potential value of miR-100-5p, this study was extended to investigate numerous non-cancerous samples (16). However, a subgroup analysis is needed to reveal more accurate conclusions in future studies. In addition, even though predictions were performed on an array of candidate genes, only two genes (RAC1 and IGF1R) have been experimentally verified $(13,15)$. More candidate genes must be verified with in vivo and in vitro experiments. The nature of the present study was itself a limitation and a prospective cohort study is expected to be conducted to verify the functions of miR-100-5p in HCC.

In conclusion, $\mathrm{miR}-100-5 \mathrm{p}$ was significantly downregulated in HCC based on the meta-analysis performed in the present study. The downregulation of miR-100-5p was found to be closely associated with a poorer prognosis and poorer clinical characteristics, including NAFLD, in patients with HCC, which indicated that miR-100-5p may function in the development and progression of HCC through multiple biological 
mechanisms. The overexpression of the 4 potential target genes (HDAC2, HDAC3, SHC1 and RAC1) of miR-100-5p were associated with poorer survival for patients with HCC. Therefore, miR-100-5p and these potential target genes may provide novel therapeutic strategies and biomarkers for the diagnosis and prognosis of patients with HCC.

\section{Acknowledgements}

Not applicable.

\section{Funding}

No funding was received.

\section{Availability of data and materials}

The datasets used and/or analyzed during the current study are available from the corresponding author on reasonable request.

\section{Authors' contributions}

QLH, HXJ and SYQ designed the study and wrote the manuscript. QLH, LT and HJN performed the preprocessing of the data and the analysis. HXJ and QLH critically revised the manuscript. All authors read and approved the final manuscript.

\section{Ethics approval and consent to participate}

Not applicable.

\section{Patient consent for publication}

Not applicable.

\section{Competing interests}

The authors declare that they have no competing interests.

\section{References}

1. Bray F, Ferlay J, Soerjomataram I, Siegel RL, Torre LA and Jemal A: Global cancer statistics 2018: GLOBOCAN estimates of incidence and mortality worldwide for 36 cancers in 185 countries. CA Cancer J Clin 68: 394-424, 2018.

2. Kudo M: Systemic therapy for hepatocellular carcinoma: 2017 update. Oncology 93 (Suppl 1): S135-S146, 2017.

3. Aguilar C, Mano $M$ and Eulalio A: MicroRNAs at the Host-bacteria interface: Host defense or bacterial offense. Trends Microbiol 27: 206-218, 2019.

4. Mollaei H, Safaralizadeh R and Rostami Z: MicroRNA replacement therapy in cancer. J Cell Physiol 234 12369-12384, 2019.

5. Li TT, Gao X, Gao L, Gan BL, Xie ZC, Zeng JJ and Chen G: Role of upregulated miR-136-5p in lung adenocarcinoma: A study of 1242 samples utilizing bioinformatics analysis. Pathol Res Pract 214: 750-766, 2018.

6. Gao L, Li SH, Tian YX, Zhu QQ, Chen G, Pang YY and Hu XH: Role of downregulated miR-133a-3p expression in bladder cancer: A bioinformatics study. Onco Targets Ther 10: 3667-3683, 2017.

7. He D, Yue Z, Li G, Chen L, Feng H and Sun J: Low serum levels of miR-101 are associated with poor prognosis of colorectal cancer patients after curative resection. Med Sci Monit 24: 7475-7481, 2018
8. Zheng Y, Tan K and Huang H: Long noncoding RNA HAGLROS regulates apoptosis and autophagy in colorectal cancer cells via sponging miR-100 to target ATG5 expression. J Cell Biochem 120: 3922-3933, 2019.

9. Wu G, Zhou W, Pan X, Sun Y, Xu H, Shi P, Li J, Gao L and Tian X: miR-100 reverses cisplatin resistance in breast cancer by suppressing HAX-1. Cell Physiol Biochem 47: 2077-2087, 2018.

10. Sun X, Liu X, Wang Y, Yang S, Chen Y and Yuan T: miR-100 inhibits the migration and invasion of nasopharyngeal carcinoma by targeting IGF1R. Oncol Lett 15: 8333-8338, 2018.

11. Shi DB, Wang YW, Xing AY, Gao JW, Zhang H, Guo XY and Gao P: C/EBP $\alpha$-induced miR-100 expression suppresses tumor metastasis and growth by targeting ZBTB7A in gastric cancer. Cancer Lett 369: 376-385, 2015.

12. Chen P, Zhao X and Ma L: Downregulation of microRNA-100 correlates with tumor progression and poor prognosis in hepatocellular carcinoma. Mol Cell Biochem 383: 49-58, 2013.

13. Zhou HC, Fang JH, Luo X, Zhang L, Yang J, Zhang C and Zhuang SM: Downregulation of microRNA-100 enhances the ICMT-Rac1 signaling and promotes metastasis of hepatocellular carcinoma cells. Oncotarget 5: 12177-12188, 2014.

14. Zhou HC, Fang JH, Shang LR, Zhang ZJ, Sang Y, Xu L, Yuan Y, Chen MS, Zheng L, Zhang Y and Zhuang SM: MicroRNAs miR-125b and miR-100 suppress metastasis of hepatocellular carcinoma by disrupting the formation of vessels that encapsulate tumour clusters. J Pathol 240: 450-460, 2016.

15. Ge YY, Shi Q, Zheng ZY, Gong J,Zeng C, Yang J and Zhuang SM: MicroRNA-100 promotes the autophagy of hepatocellular carcinoma cells by inhibiting the expression of mTOR and IGF-1R. Oncotarget 5: 6218-6228, 2014.

16. Pan WY, Zeng JH, Wen DY, Wang JY, Wang PP, Chen G and Feng ZB: Oncogenic value of microRNA-15b-5p in hepatocellular carcinoma and a bioinformatics investigation. Oncol Lett 17: 1695-1713, 2019.

17. Zhang S, Gao Y and Huang J: Interleukin-8 Gene-251 A/T (rs4073) polymorphism and coronary artery disease risk: A meta-analysis. Med Sci Monit 25: 1645-1655, 2019.

18. Zhang X, Xin G and Sun D: Serum exosomal miR-328, miR-575, miR-134 and miR-671-5p as potential biomarkers for the diagnosis of Kawasaki disease and the prediction of therapeutic outcomes of intravenous immunoglobulin therapy. Exp Ther Med 16: 2420-2432, 2018.

19. Betel D, Koppal A, Agius P, Sander C and Leslie C: Comprehensive modeling of microRNA targets predicts functional non-conserved and non-canonical sites. Genome Biol 11: R90, 2010.

20. Paraskevopoulou MD, Georgakilas G, Kostoulas N, Vlachos IS, Vergoulis T, Reczko M, Filippidis C, Dalamagas $T$ and Hatzigeorgiou AG: DIANA-microT web server v5.0: Service integration into miRNA functional analysis workflows. Nucleic Acids Res 41: W169-W173, 2013.

21. Hsu SD, Chu CH, Tsou AP, Chen SJ, Chen HC, Hsu PW, Wong YH, Chen YH, Chen GH and Huang HD: miRNAMap 2.0: Genomic maps of microRNAs in metazoan genomes. Nucleic Acids Res 36 (Database Issue): D165-D169, 2008.

22. Tsang JS, Ebert MS and van Oudenaarden A: Genome-wide dissection of microRNA functions and cotargeting networks using gene set signatures. Mol Cell 38: 140-153, 2010.

23. Vejnar CE, Blum $M$ and Zdobnov EM: miRmap web: Comprehensive microRNA target prediction online. Nucleic Acids Res 41: W165-W168, 2013.

24. Anders G, Mackowiak SD, Jens M, Maaskola J, Kuntzagk A, Rajewsky N, Landthaler M and Dieterich C: doRiNA: A database of RNA interactions in post-transcriptional regulation. Nucleic Acids Res 40 (Database Issue): D180-D186, 2012.

25. Kertesz M, Iovino N, Unnerstall U, Gaul U and Segal E: The role of site accessibility in microRNA target recognition. Nat Genet 39: 1278-1284, 2007.

26. Wang $X$ and El Naqa IM: Prediction of both conserved and nonconserved microRNA targets in animals. Bioinformatics 24: 325-332, 2008.

27. Rehmsmeier M, Steffen P, Hochsmann M and Giegerich R: Fast and effective prediction of microRNA/target duplexes. RNA 10: 1507-1517, 2004

28. Loher P and Rigoutsos I: Interactive exploration of RNA22 microRNA target predictions. Bioinformatics 28: 3322-3323, 2012.

29. Friedman RC, Farh KK, Burge CB and Bartel DP: Most mammalian mRNAs are conserved targets of microRNAs. Genome Res 19: 92-105, 2009. 
30. Calderón-González KG，Hernández-Monge J, Herrera-Aguirre ME and Luna-Arias JP: Bioinformatics tools for proteomics data interpretation. Adv Exp Med Biol 919: 281-341, 2016

31. Szklarczyk D, Morris JH, Cook H, Kuhn M, Wyder S, Simonovic M, Santos A, Doncheva NT, Roth A, Bork P, et al: The STRING database in 2017: Quality-controlled protein-protein association networks, made broadly accessible. Nucleic Acids Res 45: D362-D368, 2017.

32. Roessler S, Jia HL, Budhu A, Forgues M, Ye QH, Lee JS, Thorgeirsson SS, Sun Z, Tang ZY, Qin LX and Wang XW: A unique metastasis gene signature enables prediction of tumor relapse in early-stage hepatocellular carcinoma patients. Cancer Res 70: 10202-10212, 2010.

33. Chen X, Cheung ST, So S, Fan ST, Barry C, Higgins J, Lai KM, Ji J, Dudoit S, Ng IO, et al: Gene expression patterns in human liver cancers. Mol Biol Cell 13: 1929-1939, 2002.

34. Uhlen M, Zhang C, Lee S, Sjöstedt E, Fagerberg L, Bidkhori G, Benfeitas R, Arif M, Liu Z, Edfors F, et al: A pathology atlas of the human cancer transcriptome. Science 357: pii: eaan2507, 2017.

35. Jiao XD, Qin BD, You P, Cai J and Zang YS: The prognostic value of TP53 and its correlation with EGFR mutation in advanced non-small cell lung cancer, an analysis based on cBioPortal data base. Lung Cancer 123: 70-75, 2018.

36. Ryan M, Wong WC, Brown R, Akbani R, Su X, Broom B, Melott J and Weinstein J: TCGASpliceSeq a compendium of alternative mRNA splicing in cancer. Nucleic Acids Res 44: D1018-D1022, 2016.

37. Zhang R, Lin P, Yang X, He RQ, Wu HY, Dang YW, Gu YY, Peng ZG, Feng ZB and Chen G: Survival associated alternative splicing events in diffuse large B-cell lymphoma. Am J Transl Res 10: 2636-2647, 2018

38. Li Y, Sun N, Lu Z, Sun S, Huang J, Chen Z and He J: Prognostic alternative mRNA splicing signature in non-small cell lung cancer. Cancer Lett 393: 40-51, 2017.

39. Xiao F, Bai Y, Chen Z, Li Y, Luo L, Huang J, Yang J, Liao H and Guo L: Downregulation of HOXA1 gene affects small cell lung cancer cell survival and chemoresistance under the regulation of miR-100. Eur J Cancer 50: 1541-1554, 2014.

40. Guo P, Xiong X, Zhang S and Peng D: miR-100 resensitizes resistant epithelial ovarian cancer to cisplatin. Oncol Rep 36 3552-3558, 2016.

41. Qin X, Yu S, Zhou L, Shi M, Hu Y, Xu X, Shen B, Liu S, Yan D and Feng J: Cisplatin-resistant lung cancer cell-derived exosomes increase cisplatin resistance of recipient cells in exosomal miR-100-5p-dependent manner. Int J Nanomedicine 12 : 3721-3733, 2017.

42. Wang M, Ren D, Guo W, Wang Z, Huang S, Du H, Song L and Peng $X$ : Loss of miR-100 enhances migration, invasion, epithelial-mesenchymal transition and stemness properties in prostate cancer cells through targeting Argonaute 2. Int J Oncol 45: 362-372, 2014.

43. Leite KR, Sousa-Canavez JM, Reis ST, Tomiyama AH, Camara-Lopes LH, Sañudo A, Antunes AA and Srougi M: Change in expression of miR-let7c, miR-100, and miR-218 from high grade localized prostate cancer to metastasis. Urol Oncol 29: 265-269, 2011.

44. Zhang H, Wang J, Wang Z, Ruan C, Wang L and Guo H: Serum miR-100 is a potential biomarker for detection and outcome prediction of glioblastoma patients. Cancer Biomark 24: 43-49, 2019.

45. Azizmohammadi S, Azizmohammadi S, Safari A, Kosari N, Kaghazian M, Yahaghi E and Seifoleslami M: The role and expression of miR-100 and miR-203 profile as prognostic markers in epithelial ovarian cancer. Am J Transl Res 8: 2403-2410, 2016.

46. Petrelli A, Perra A, Schernhuber K, Cargnelutti M, Salvi A, Migliore C, Ghiso E, Benetti A, Barlati S, Ledda-Columbano GM, et al: Sequential analysis of multistage hepatocarcinogenesis reveals that miR-100 and PLK1 dysregulation is an early event maintained along tumor progression. Oncogene 31: 4517-4526, 2012.

47. Varnholt H, Drebber U, Schulze F, Wedemeyer I, Schirmacher P, Dienes HP and Odenthal M: MicroRNA gene expression profile of hepatitis C virus-associated hepatocellular carcinoma. Hepatology 47: 1223-1232, 2008.

48. Wang Y, Gao Y, Shi W, Zhai D, Rao Q, Jia X, Liu J, Jiao X and Du Z: Profiles of differential expression of circulating microRNAs in hepatitis B virus-positive small hepatocellular carcinoma. Cancer Biomark 15: 171-180, 2015.
49. Tsai CT, Zulueta MML and Hung SC: Synthetic heparin and heparan sulfate: Probes in defining biological functions. Curr Opin Chem Biol 40: 152-159, 2017.

50. Li JP and Kusche-Gullberg M: Heparan Sulfate: Biosynthesis, structure, and function. Int Rev Cell Mol Biol 325: 215-273, 2016.

51. Weiss RJ, Esko JD and Tor Y: Targeting heparin and heparan sulfate protein interactions. Org Biomol Chem 15: 5656-5668, 2017.

52. Cassinelli G, Zaffaroni N and Lanzi C: The heparanase/heparan sulfate proteoglycan axis: A potential new therapeutic target in sarcomas. Cancer Lett 382: 245-254, 2016.

53. Ling L, Tan SK, Goh TH, Cheung E, Nurcombe V, van Wijnen AJ and Cool SM: Targeting the heparin-binding domain of fibroblast growth factor receptor 1 as a potential cancer therapy. Mol Cancer 14: 136, 2015.

54. Dudás J, Bocsi J, Fullár A, Baghy K, Füle T, Kudaibergenova S and Kovalszky I: Heparin and liver heparan sulfate can rescue hepatoma cells from topotecan action. Biomed Res Int 2014: 765794, 2014

55. Gao J, Wang Y, Li W, Zhang J, Che Y, Cui X, Sun B and Zhao G Loss of histone deacetylase 2 inhibits oxidative stress induced by high glucose via the HO-1/SIRT1 pathway in endothelial progenitor cells. Gene 678: 1-7, 2018.

56. Li Y, Zhou M, Lv X, Song L, Zhang D, He Y, Wang M, Zhao X, Yuan X, Shi G and Wang D: Reduced activity of HDAC3 and increased acetylation of histones H3 in peripheral blood mononuclear cells of patients with rheumatoid arthritis. J Immunol Res 2018: 7313515, 2018.

57. Li S, Wang F, Qu Y, Chen X, Gao M, Yang J, Zhang D, Zhang N, $\mathrm{Li} \mathrm{W}$ and Liu H: HDAC2 regulates cell proliferation, cell cycle progression and cell apoptosis in esophageal squamous cell carcinoma EC9706 cells. Oncol Lett 13: 403-409, 2017.

58. Peng Z, Zhou W, Zhang C, Liu H and Zhang Y: Curcumol controls choriocarcinoma stem-like cells self-renewal via repression of DNA Methyltransferase (DNMT)- and histone deacetylase (HDAC)-mediated epigenetic regulation. Med Sci Monit 24: 461-472, 2018.

59. Liu L, Lin W, Zhang Q, Cao W and Liu Z: TGF- $\beta$ induces miR-30d down-regulation and podocyte injury through Smad2/3 and HDAC3-associated transcriptional repression. J Mol Med (Berl) 94: 291-300, 2016.

60. Mao QD, Zhang W, Zhao K, Cao B, Yuan H, Wei LZ, Song MQ and Liu XS: MicroRNA-455 suppresses the oncogenic function of HDAC2 in human colorectal cancer. Braz J Med Biol Res 50: e6103, 2017.

61. Yang Y, Zhang J, Wu T, Xu X, Cao G, Li H and Chen X: Histone deacetylase 2 regulates the doxorubicin (Dox) resistance of hepatocarcinoma cells and transcription of ABCB1. Life Sci 216: 200-206, 2019

62. Zhao H, Yu Z, Zhao L, He M, Ren J, Wu H, Chen Q, Yao W and Wei M: HDAC2 overexpression is a poor prognostic factor of breast cancer patients with increased multidrug resistance-associated protein expression who received anthracyclines therapy. Jpn J Clin Oncol 46: 893-902, 2016.

63. Cui Z, Xie M, Wu Z and Shi Y: Relationship between histone deacetylase 3 (HDAC3) and breast cancer. Med Sci Monit 24: 2456-2464, 2018

64. Wu LM, Yang Z, Zhou L, Zhang F, Xie HY, Feng XW, Wu J and Zheng SS: Identification of histone deacetylase 3 as a biomarker for tumor recurrence following liver transplantation in $\mathrm{HBV}$-associated hepatocellular carcinoma. PLoS One 5: e14460, 2010.

65. Lebiedzinska-Arciszewska M, Oparka M, Vega-Naredo I, Karkucinska-Wieckowska A, Pinton P, Duszynski J and Wieckowski MR: The interplay between p66Shc, reactive oxygen species and cancer cell metabolism. Eur J Clin Invest 45 (Suppl 1): S25-S31, 2015.

66. Wong N, Chan A, Lee SW, Lam E, To KF, Lai PB, Li XN, Liew CT and Johnson PJ: Positional mapping for amplified DNA sequences on 1q21-q22 in hepatocellular carcinoma indicates candidate genes over-expression. J Hepatol 38: 298-306, 2003.

67. Kisielow M, Kleiner S, Nagasawa M, Faisal A and Nagamine Y: Isoform-specific knockdown and expression of adaptor protein ShcA using small interfering RNA. Biochem J 363: 1-5, 2002.

68. Zhang L, Zhu S, Shi X and Sha W: The silence of p66(Shc) in HCT8 cells inhibits the viability via PI3K/AKT/Mdm-2/p53 signaling pathway. Int J Clin Exp Pathol 8: 9097-9104, 2015.

69. Yukimasa S, Masaki T, Yoshida S, Uchida N, Watanabe S, Usuki H, Yoshiji H, Maeta T, Ebara K, Nakatsu T, et al: Enhanced expression of $\mathrm{p} 46 \mathrm{Shc}$ in the nucleus and $\mathrm{p} 52 \mathrm{Shc}$ in the cytoplasm of human gastric cancer. Int J Oncol 26: 905-911, 2005. 
70. Muniyan S, Chou YW, Tsai TJ, Thomes P, Veeramani S, Benigno BB, Walker LD, McDonald JF, Khan SA, Lin FF, et al: p66Shc longevity protein regulates the proliferation of human ovarian cancer cells. Mol Carcinog 54: 618-631, 2015.

71. Rajendran M, Thomes P, Zhang L, Veeramani S and Lin MF: p66Shc-a longevity redox protein in human prostate cancer progression and metastasis: p66Shc in cancer progression and metastasis. Cancer Metastasis Rev 29: 207-222, 2010.

72. Yoshida S, Kornek M, Ikenaga N, Schmelzle M, Masuzaki R, Csizmadia E, Wu Y, Robson SC and Schuppan D: Sublethal heat treatment promotes epithelial-mesenchymal transition and enhances the malignant potential of hepatocellular carcinoma. Hepatology 58: 1667-1680, 2013.

73. Bid HK, Roberts RD, Manchanda PK and Houghton PJ: RAC1: An emerging therapeutic option for targeting cancer angiogenesis and metastasis. Mol Cancer Ther 12: 1925-1934, 2013

74. Cheng H, Wang W, Wang G, Wang A, Du L and Lou W: Silencing ras-related $\mathrm{C} 3$ botulinum toxin substrate 1 inhibits growth and migration of hypopharyngeal squamous cell carcinoma via the P38 mitogen-activated protein kinase signaling pathway. Med Sci Monit 24: 768-781, 2018

75. Liu B, Xiong J, Liu G, Wu J, Wen L, Zhang Q and Zhang C: High expression of Racl is correlated with partial reversed cell polarity and poor prognosis in invasive ductal carcinoma of the breast. Tumour Biol 39: 1010428317710908, 2017.

76. Yoon C, Cho SJ, Chang KK, Park DJ, Ryeom SW and Yoon SS: Role of Rac1 pathway in epithelial-to-mesenchymal transition and cancer stem-like cell phenotypes in gastric adenocarcinoma. Mol Cancer Res 15: 1106-1116, 2017.

77. Niu X, Gao Z, Qi S, Su L, Yang N, Luan X, Li J, Zhang Q, An Y and Zhang S: Macropinocytosis activated by oncogenic Dbl enables specific targeted delivery of Tat/pDNA nano-complexes into ovarian cancer cells. Int J Nanomedicine 13: 4895-4911, 2018

78. Poudel KR, Roh-Johnson M, Su A, Ho T, Mathsyaraja H, Anderson S, Grady WM, Moens CB, Conacci-Sorrell M, Eisenman RN and Bai J: Competition between TIAM1 and membranes balances endophilin A3 activity in cancer metastasis. Dev Cell 45: 738-752.e6, 2018.

79. Aspenström P: Activated Rho GTPases in cancer-the beginning of a new paradigm. Int J Mol Sci 19: pii: E3949, 2018.

80. Ching YP, Leong VY, Lee MF, Xu HT, Jin DY and Ng IO: $\mathrm{P} 21$-activated protein kinase is overexpressed in hepatocellular carcinoma and enhances cancer metastasis involving c-Jun NH2-terminal kinase activation and paxillin phosphorylation. Cancer Res 67: 3601-3608, 2007.

81. Zhu S, Jin J, Gokhale S, Lu AM, Shan H, Feng J and Xie P: Genetic alterations of TRAF proteins in human cancers. Front Immunol 9: 2111, 2018

82. Reder H, Wagner S, Gamerdinger $U$, Sandmann $S$, Wuerdemann N, Braeuninger A, Dugas M, Gattenloehner S, Klussmann JP and Wittekindt C: Genetic alterations in human papillomavirus-associated oropharyngeal squamous cell carcinoma of patients with treatment failure. Oral Oncol 93: 59-65, 2019.

83. Sajnani K, Islam F, Smith RA, Gopalan V and Lam AK: Genetic alterations in Krebs cycle and its impact on cancer pathogenesis. Biochimie 135: 164-172, 2017.

84. Jonckheere N, Vasseur R and Van Seuningen I: The cornerstone K-RAS mutation in pancreatic adenocarcinoma: From cell signaling network, target genes, biological processes to therapeutic targeting. Crit Rev Oncol Hematol 111: 7-19, 2017.

85. Song X, Zeng Z, Wei $\mathrm{H}$ and Wang Z: Alternative splicing in cancers: From aberrant regulation to new therapeutics. Semin Cell Dev Biol 75: 13-22, 2018

86. Climente-González H, Porta-Pardo E, Godzik A and Eyras E: The functional impact of alternative splicing in cancer. Cell Rep 20: 2215-2226, 2017.

87. Xie M, Dart DA, Owen S, Wen X, Ji J and Jiang W: Insights into roles of the miR-1, -133 and -206 family in gastric cancer (Review). Oncol Rep 36: 1191-1198, 2016.

88. Teplyuk NM, Uhlmann EJ, Gabriely G, Volfovsky N, Wang Y, Teng J, Karmali P, Marcusson E, Peter M, Mohan A, et al: Therapeutic potential of targeting microRNA-10b in established intracranial glioblastoma: First steps toward the clinic. EMBO Mol Med 8: 268-287, 2016.
89. Li W, Xie L, He X, Li J, Tu K, Wei L, Wu J, Guo Y, Ma X, Zhang $\mathrm{P}$, et al: Diagnostic and prognostic implications of microRNAs in human hepatocellular carcinoma. Int J Cancer 123: 1616-1622, 2008.

90. Su H, Yang JR, Xu T, Huang J, Xu L, Yuan Y and Zhuang SM: MicroRNA-101, down-regulated in hepatocellular carcinoma, promotes apoptosis and suppresses tumorigenicity. Cancer Res 69: 1135-1142, 2009.

91. Burchard J, Zhang C, Liu AM, Poon RT, Lee NP, Wong KF, Sham PC, Lam BY, Ferguson MD, Tokiwa G, et al: microRNA-122 as a regulator of mitochondrial metabolic gene network in hepatocellular carcinoma. Mol Sys Biol 6: 402, 2010.

92. Sato F, Hatano E, Kitamura K, Myomoto A, Fujiwara T, Takizawa S, Tsuchiya S, Tsujimoto G, Uemoto $S$ and Shimizu K: MicroRNA profile predicts recurrence after resection in patients with hepatocellular carcinoma within the Milan Criteria. PLoS One 6: e16435, 2011.

93. Noh JH, Chang YG, Kim MG, Jung KH, Kim JK, Bae HJ, Eun JW, Shen Q, Kim SJ, Kwon SH, et al: MiR-145 functions as a tumor suppressor by directly targeting histone deacetylase 2 in liver cancer. Cancer Lett 335: 455-462, 2013

94. Wang PR, Xu M, Toffanin S, Li Y, Llovet JM and Russell DW Induction of hepatocellular carcinoma by in vivo gene targeting. Proc Natl Acad Sci USA 109: 11264-11269, 2012.

95. Morita K, Shirabe K, Taketomi A, Soejima Y, Yoshizumi T, Uchiyama H, Ikegami T, Yamashita Y, Sugimachi K, Harimoto $\mathrm{N}$, et al: Relevance of microRNA-18a and microRNA-199a-5p to hepatocellular carcinoma recurrence after living donor liver transplantation. Liver Transpl 22: 665-676, 2016

96. Shih TC, Tien YJ, Wen CJ, Yeh TS, Yu MC, Huang CH, Lee YS, Yen TC and Hsieh SY: MicroRNA-214 downregulation contributes to tumor angiogenesis by inducing secretion of the hepatoma-derived growth factor in human hepatoma. J Hepatol 57: 584-591, 2012.

97. Wojcicka A, Swierniak M, Kornasiewicz O, Gierlikowski W, Maciag M, Kolanowska M, Kotlarek M, Gornicka B, Koperski L, Niewinski G, et al: Next generation sequencing reveals microRNA isoforms in liver cirrhosis and hepatocellular carcinoma. Int J Biochem Cell Biol 53: 208-217, 2014.

98. Shen J, Siegel AB, Remotti H, Wang Q and Santella RM: Identifying microRNA panels specifically associated with hepatocellular carcinoma and its different etiologies. Hepatoma Res 2: 151-162, 2016

99. Lou W, Liu J, Ding B, Chen D, Xu L, Ding J, Jiang D, Zhou L, Zheng S and Fan W: Identification of potential miRNA-mRNA regulatory network contributing to pathogenesis of HBV-related HCC. J Transl Med 17: 7, 2019.

100. Murakami Y, Kubo S, Tamori A, Itami S, Kawamura E, Iwaisako K, Ikeda K, Kawada N, Ochiya T and Taguchi YH: Comprehensive analysis of transcriptome and metabolome analysis in Intrahepatic Cholangiocarcinoma and hepatocellular carcinoma. Sci Rep 5: 16294, 2015.

101. Ghosh A, Ghosh A, Datta S, Dasgupta D, Das S, Ray S, Gupta S, Datta S, Chowdhury A, Chatterjee R, et al: Hepatic miR-126 is a potential plasma biomarker for detection of hepatitis B virus infected hepatocellular carcinoma. Int J Cancer 138: 2732-2744, 2016.

102. Peng H, Ishida M, Li L, Saito A, Kamiya A, Hamilton JP, Fu R, Olaru AV, An F, Popescu I, et al: Pseudogene INTS6P1 regulates its cognate gene INTS6 through competitive binding of miR-17-5p in hepatocellular carcinoma. Oncotarget 6: 5666-5677, 2015.

103. Zhang Y, Wen DY, Zhang R, Huang JC, Lin P, Ren FH, Wang X, He Y, Yang H, Chen G and Luo DZ: A preliminary investigation of PVT1 on the effect and mechanisms of hepatocellular carcinoma: Evidence from clinical data, a meta-analysis of 840 cases and in vivo validation. Cell Physiol Biochem 47: 2216-2232, 2018.

104. Shi J, Ye G, Zhao G, Wang X, Ye C, Thammavong K, Xu J and Dong J: Coordinative control of G2/M phase of the cell cycle by non-coding RNAs in hepatocellular carcinoma. PeerJ 6: e5787, 2018.

This work is licensed under a Creative Commons Attribution-NonCommercial-NoDerivatives 4.0 International (CC BY-NC-ND 4.0) License. 